\title{
Premating barriers in young sympatric snail species
}

Arina L. Maltseva ${ }^{1 凶}$, Marina A. Varfolomeeva ${ }^{1}$, Arseniy A. Lobov ${ }^{1,2}$, Polina O. Tikanova ${ }^{1,3}$, Egor A. Repkin ${ }^{1}$, Irina Y. Babkina ${ }^{1}$, Marina Panova ${ }^{1,4}$, Natalia A. Mikhailova ${ }^{1,5}$ \& Andrei I. Granovitch ${ }^{1}$

Sympatric coexistence of recently diverged species raises the question of barriers restricting the gene flow between them. Reproductive isolation may be implemented at several levels, and the weakening of some, e.g. premating, barriers may require the strengthening of the others, e.g. postcopulatory ones. We analysed mating patterns and shell size of mates in recently diverged closely related species of the subgenus Littorina Neritrema (Littorinidae, Caenogastropoda) in order to assess the role of premating reproductive barriers between them. We compared mating frequencies observed in the wild with those expected based on relative densities using partial canonical correspondence analysis. We introduced the fidelity index (FI) to estimate the relative accuracy of mating with conspecific females and precopulatory isolation index $\left(\mathrm{I}_{\mathrm{PC}}\right)$ to characterize the strength of premating barriers. The species under study, with the exception of $L$. arcana, clearly demonstrated preferential mating with conspecifics. According to $\mathrm{FI}$ and $\mathrm{I}_{\mathrm{PC}}$ L. fabalis and $L$. compressa appeared reliably isolated from their closest relatives within Neritrema. Individuals of these two species tend to be smaller than those of the others, highlighting the importance of shell size changes in gastropod species divergence. L. arcana males were often found in pairs with $L$. saxatilis females, and no interspecific size differences were revealed in this sibling species pair. We discuss the lack of discriminative mate choice in the sympatric populations of $L$. arcana and $L$. saxatilis, and possible additional mechanisms restricting gene flow between them.

Reproductive isolation is a keystone of the biological concept of the species ${ }^{1}$. The emergence of at least partial reproductive barriers is generally accepted as a crucial event in the evolutionary history of species, allowing them not only to diverge but also to persist in time ${ }^{2,3}$. Depending on the stage of the reproduction process, reproductive barriers in internal fertilizers are classified into premating isolation (PMI; anything that affects the existing mating patterns), postmating prezygotic (PMPZ) isolation (mechanisms acting between copulation and zygote formation), and postzygotic isolation (aspects associated with the ability to develop, viability and fertility of hybrids) $)^{2,4}$.

Observations and theoretical models support the idea that PMI evolves faster than PMPZ and postzygotic mechanisms $s^{5,6}$. In the course of speciation, PMI originates from the phenomenon of assortative mating. Several proximate mechanisms contribute to assortative mating and PMI: ecological isolation, including habitatpreference and habitat-associated fitness isolation; temporal isolation, with a shift in the timing of reproduction; and sexual isolation, when mate choice affects mating pattern ${ }^{1,2,7,8}$. PMI through assortative mating is usually considered as a possible driving force of incipient species divergence in sympatry, affecting the likelihood of speciation events ${ }^{9-14}$. PMPZ reproductive isolation in animals is less studied than premating or postzygotic isolation ${ }^{6}$. However, a few studies on model systems show that a weakening of PMI may require the strengthening of PMPZ barriers, thus closing the gap in reproductive barriers ${ }^{6,15}\left(\right.$ but see $\left.^{16}\right)$.

In this study, we evaluate the total efficacy of PMI in a group of closely related sympatric species of intertidal gastropods of the genus Littorina. A high microhabitat diversity in the intertidal makes it possible for morphologically and ecologically diverse organisms to coexist and to engage in complex interactions ${ }^{17-20}$. Moreover, the environmental heterogeneity of the intertidal zone may be a driving force of ecological speciation ${ }^{21,22}$. Indeed, many of the species sympatrically inhabiting intertidal areas are phylogenetically close and must have formed as a result of recent ecological divergence events, e.g. Fucus algae ${ }^{23-25}$; Urosalpinx gastropods ${ }^{26}$; Idotea crustaceans ${ }^{27}$. Effective reproductive barriers may be expected in sympatric sister-species, because they have to be strongly

\footnotetext{
${ }^{1}$ Department of Invertebrate Zoology, St Petersburg State University, St Petersburg, Russia. ${ }^{2}$ Laboratory of Regenerative Biomedicine, Institute of Cytology Russian Academy of Sciences, St Petersburg, Russia. ${ }^{3}$ Institute of Molecular Biotechnology of the Austrian Academy of Sciences (IMBA), Vienna, Austria. ${ }^{4}$ Department of Marine Sciences - Tjärnö, University of Gothenburg, Gothenburg, Sweden. ${ }^{5}$ Centre of Cell Technologies, Institute of Cytology Russian Academy of Sciences, St Petersburg, Russia. ${ }^{\boxplus}$ email: arina.maltseva@spbu.ru
} 
isolated to persist either after sympatric speciation or in secondary contact after allopatry ${ }^{2}$. The primary role should belong to mechanisms of premating (or, in case of external fertilizers, prezygotic) isolation since they are the fastest-evolving ones ${ }^{6}$.

Species of the Littorina, the subgenus Neritrema (Littorinidae, Caenogasropoda), are a textbook example of recently diverged species occurring in sympatry. Five of them live together at the shores of European Northern Atlantic seas: L. obtusata (Linnaeus, 1758) and L. fabalis (W. Turton, 1825) ("obtusata" group of species) and L. saxatilis (Olivi 1792), L. compressa Jeffreys, 1865 and L. arcana Hannaford Ellis, 1978 ("saxatilis" group of species). All Neritrema species are dioecious polygamic internal fertilizers showing no obvious sexual dimorphism in shell shape ${ }^{28}$; males are the choosing sex, while females (or other partners, see below) are mostly passive during copulation ${ }^{29-32}$.

High-density populations of the Neritrema species sympatrically coexist in the intertidal zone. Being very close phylogenetically, they are characterized by similar biological and morphological features and are often regarded as cryptic species ${ }^{33-36}$. This raises a number of intriguing questions. How do these species maintain species identity? What ensures effective reproductive isolation between these evolutionarily young species? What is the relative importance of premating barriers in their reproductive isolation?

The mating patterns of Littorinids have been extensively studied, with the role of assortative mating as a possible driver of speciation being given special attention ${ }^{30-32,37-49}$. For example, research on L. saxatilis and L. fabalis has focused on the role of sexual selection in the divergence of ecotypes and the restriction of the gene flow between them ${ }^{31,42,43,46,50}$. However, to the best of our knowledge, no analysis of interspecific mating patterns involving all the five North Atlantic sympatric periwinkles in wild populations has ever been made.

In this study, we estimated the contribution of premating barriers to reproductive isolation between recently diverged species in nature by tracing interspecific copulatory activity among already diverged closely related species instead of examining assortative mating in populations at the initial stages of their divergence (e.g. between ecotypes). Such an approach makes it possible (a) to deal with true species after the speciation event rather than with specialized forms, such as eco- or morphotypes, which might never become species; (b) to consider several species at the same time, not only the most contrasting forms; (c) to assess an actual mating activity in a natural population rather than in laboratory experiments, the results of which are not always easy to extrapolate to natural conditions.

The objective of the study was to describe in detail the mating activity in the chosen model species in order to estimate the reliability of PMI and to assess the contribution of possible proximate mechanisms of PMI to reproductive isolation. To achieve this, we registered mating activity in natural populations of five sympatric Neritrema species in the Barents Sea taking into account the population characteristics such as species densities, distribution pattern, and sex ratio, and the individual characteristics such as shell size, maturity, and trematode infection. The precopulatory isolation index $\left(\mathrm{I}_{\mathrm{PC}}\right)$ based on the joint isolation index ${ }^{51}$ and $\mathrm{I}_{\mathrm{PSI}}{ }^{52}$ was used to describe total PMI, while a newly suggested male fidelity index (FI) was used to show an excessive mating with conspecific females compared to the null hypothesis of random mating.

We aimed (a) to quantify the frequency of interspecific mating, first of all, whether males mate with heterospecific females; (b) to list all distinct passive partner types that can mate with males of the Neritrema species in the wild, and to compare the similarity of such mating spectra among species of active partners and among types of passive partners; (c) to characterize the accuracy of mating with conspecific females using the newly suggested male fidelity index (FI, prevalence of matings with conspecific females among all mating committed by males of a given species); (d) to assess deviations from a random mating pattern simultaneously for males of all the species and all the types of passive partners using partial canonical correspondence analysis ${ }^{53,54}$ (pCCA), which would allow one to highlight general patterns by partialling out the effects of background factors (e.g. site and intertidal level) on mating frequencies; (e) to quantify total PMI using the precopulatory isolation index $\mathrm{I}_{\mathrm{PC}}$; (f) to evaluate sizes of copulating partners of different species to examine the potential importance of shell size in interspecies PMI.

\section{Materials and methods}

Collection of copulating pairs. Individuals of five Littorina species: L. arcana, L. compressa, L. saxatilis ("saxatilis" group) and L. fabalis, L. obtusata ("obtusata" group) involved in copulation were collected at two distant intertidal sites at the Barents Sea coast: Dalnye Zelentsy, Oscar Bay, Russia $\left(69^{\circ} 07^{\prime} 01.0^{\prime \prime} \mathrm{N} 36^{\circ} 04^{\prime} 07.5^{\prime \prime} \mathrm{E}\right.$; 05-15 July 2015) and Kiberg, Varangerford, Norway (70¹6'55.1" N 3058'27.6" E; 16-25 June 2016 and 16-25 June 2017). Both sites were represented by the flat stony-gravel littorals, overgrown with macrophytes of similar species composition. The samples were taken during the spring-summer peak of reproductive activity of all the species involved in the study ${ }^{33,55-57}$.

Pairs were collected from a restricted area of the intertidal zone $(\sim 25 \mathrm{~m}$ wide), separately from the upper and lower parts, because these are inhabited by different sets of species. These parts were recognized based on biocenotic characteristics: the lower part is overgrown with fucoid macroalgae (including Fucus vesiculosus, Ascophyllum nodosum and F. serratus), while the upper part has large boulders and rocky ledges without macrophytes, smaller boulders and pebbles with some scattered clumps of F. vesiculosus (more details in Supplement $\mathrm{S} 1$ ). The two sampling parts within the intertidal zones did not contact, being 3-5 $\mathrm{m}$ apart.

The snails were collected at low tide over several days. Copulating pairs were recognized based on their typical position (Fig. 1A). The event of penis insertion into the mantle cavity of a passive partner was verified visually while separating partners from each other (Fig. 1B, Supplement S2). All such events were considered as copulations though the penis insertion into the female bursa copulatrix (true copulation) could not be verified in this way. This means that true copulations were analysed together with copulation attempts. All the pairs of snails involved in the analysis are hereafter referred to as "copulating pairs", following the conventional use of 


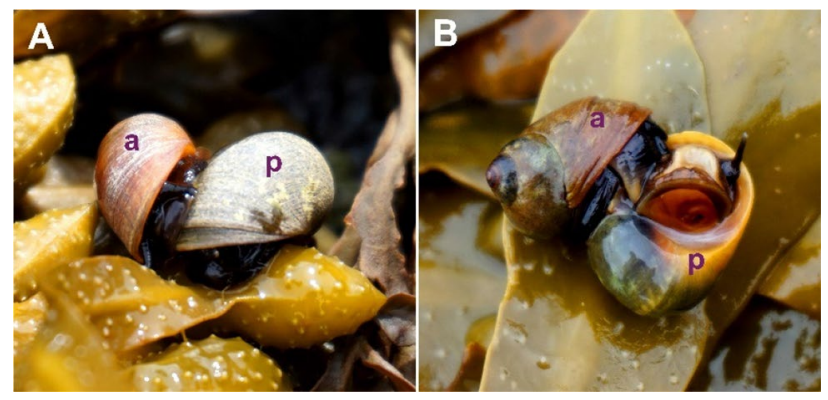

Figure 1. Littorina obtusata pair in copulation. (A) Typical position of copulating snails on the substrate. (B) A turned pair with an inserted penis visible. a-active partner (inserting penis); $\mathrm{p}$-passive partner (accepting penis).

this term in similar studies on Littorina mating activity ${ }^{30-32,37-44,46}$. The pairs of snails considered as copulating were put into plastic bags, each pair into a separate bag, without marking either active (inserting penis) or passive (accepting penis) partners (Fig. 1B). Thus, it was impossible to determine later which of the partners was the active one in male-male pairs. The collected pairs were transferred to the laboratory, where their shell height was measured with calipers. After that, the snails were dissected to determine their maturity (based on welldeveloped genitalia and auxiliary glands), sex, trematode infection (based on the presence of parthenitae stages in the tissues of hepatopancreas), and the species.

In total, we collected 317 copulating pairs: 139 pairs at Dalnye Zelentsy in 2015 (91 at the upper and 48 at the lower intertidal), 89 pairs at Kiberg in 2016 (26 at the upper and 63 at the lower intertidal), and 89 pairs in Kiberg in 2017 ( 40 at the upper and 49 at the lower intertidal). The copulating pairs were categorised by the type of active and passive partner to obtain observed copulation frequencies. Male-male pairs, in which it was impossible to determine which of the partners was the active one, were recorded as 0.5 counts for both possible combinations.

Species identification of the Neritrema snails is notoriously difficult and requires considerable skills and an intimate knowledge of the molluscan morphology and anatomy. Morphological identification was performed by experienced specialists (Andrei Granovitch and Natalia Mikhailova) based on the diagnoses from the fundamental review ${ }^{33}$ and previous studies of these species $^{36,58-61}$.

Three species of the "saxatilis" group (L. compressa, L. arcana and L. saxatilis) have a very similar morphology. Females can be distinguished by their reproductive system: females of $L$. compress $a$ and $L$. arcana are oviparous, whereas L. saxatilis is ovoviviparous. They also differ in the structure of the distal parts of the female reproductive system, that is, the relative size of the albumen, capsule and jelly glands, as well as in the size and shape of the bursa copulatrix, which is broad and long in L. arcana and short and slim in L. compressa. Species identification of males of $L$. saxatilis and L. arcana was based on penis morphology $\mathrm{y}^{33,62}$ : the number of mamilliform glands and the shape of a filament (Fig. 2). Two or more rows of small numerous mamilliform penial glands and triangular filament were definitive for L. arcana (Fig. 2C,E,F); the distribution of glands on the penis surface was interpreted as two or more rows only if at least two glands were opposite to each other (Fig. 2F). Males with one row of large distal glands (not more than six in number) and a short filament were identified as L. compressa. Males with one row of numerous (more than six) small mamilliform penial glands and a triangular filament were classified as L. saxatilis 1 row (Fig. 2A,B,H). If one or more glands were out of the row, but not in an opposite position (in an intermediate position), such males were considered in a separate category, L. saxatilis 1.5 row (Fig. 2D,G), as possible hybrids between L. saxatilis and L. arcana ${ }^{59}$.

At present, there is no reliable specific-specific marker for identification of males of L. saxatilis and L. arcana by genotyping. Besides, some of the females with L. arcana morphology could have been hybrids ${ }^{63}$. However, the frequency of hybrids between $L$. saxatilis and L. arcana in the natural populations is probably very low. It was estimated to be $<2 \%$ by Warwick et al. ${ }^{63}$, while Stankowski et al. ${ }^{64}$ found no hybrids at all among 3,092 snails analysed.

Two species of the "obtusata" group (L. obtusata and L. fabalis) are oviparous and have a similar shell morphology in the study sites. The females of these species were identified based on the differences in the morphology of the bursa copulatrix, which is long, reaching up the albumen gland in L. obtusata and short and almost indiscernible in L. fabalis. The males of these two species differ in the number and shape of mamilliform glands and the morphology of the penial filament. The penis of $L$. fabalis has not more than six relatively large glands, located in the middle part of the organ; the filament is thin and long and may be longer than the basal penis part. The males with several rows of small glands on the penis with a short and thick filament were identified as L. obtusata ${ }^{33}$.

Immature or trematode-castrated (ITC) individuals were impossible to identify to the species level due to absence of well-developed reproductive organs (often even sex-identifying organs are underdeveloped or resorbed). These individuals were attributed only to their species group ("saxatilis" or "obtusata"), based on shell features $^{33}$. These two groups were considered together due to their unidentified species/sexual status.

Description of Littorina species composition on the shore. Snails were sampled from randomly positioned square frames with an area of $0.04 \mathrm{~m}^{2}(20 \mathrm{~cm} \times 20 \mathrm{~cm})$ from the upper (six replicate samples) and the lower (ten replicate samples) parts of the intertidal zone at each study site. A greater number of replicate samples at the lower intertidal was associated with the fact that its area was approximately 1.5 times larger than that of 

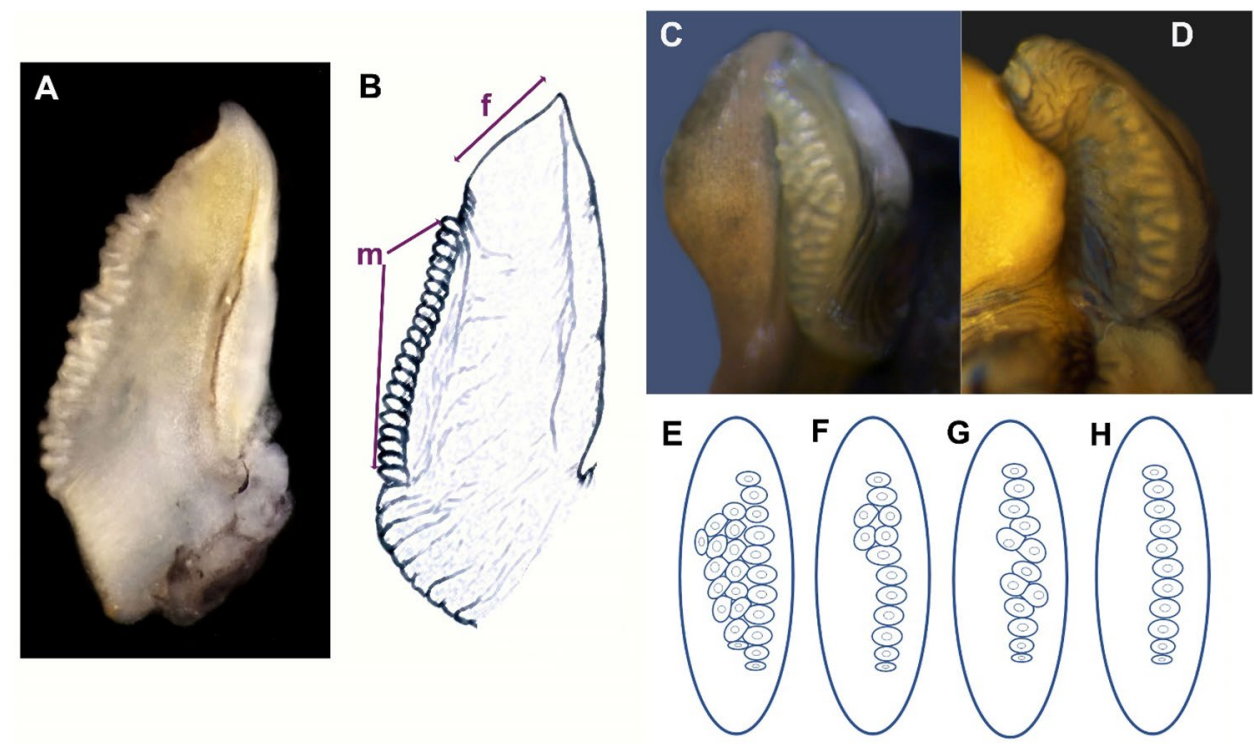

Figure 2. Morphology of a Littorina penis. (A) A photograph of L. saxatilis penis; (B) a scheme of a penis showing features important for identification-filament (f) and a row of mamilliform glands (m); (C-H) examples of penises with different numbers of gland rows; $(\mathbf{C})$ multiple rows corresponds to scheme $(\mathbf{E})$ (identified as L. arcana); (D) 1.5 rows (there are no glands in an opposite position, although several glands are out of the row) corresponds to scheme (G) (identified as L. saxatilis 1.5, presumably hybrids between L. arcana and L. saxatilis); (F) two rows of penial glands, as two pairs of glands are in opposite position (identified as L. arcana); (H) one even row of penial glands (identified as L. saxatilis 1 row).

the upper intertidal. All the snails within the quadrat were collected, put into a plastic bag and transported to the laboratory, where they were measured, identified down to the species and subjected to size measurements as well as to assessment of maturity, sex, and trematode infection as described above.

The species composition of the snails was different in the upper and the lower parts of the intertidal zone. All the five species inhabited the lower intertidal, but only L. arcana, L. saxatilis and L. obtusata were recorded in the upper intertidal (L. obtusata was absent there in the Dalnye Zelentsy, 2015) (Supplement S3). For this reason, the mating patterns of the snails from the upper and the lower intertidal zone were analysed separately. Mean relative densities were used to calculate expected copulation frequencies under the random mating hypothesis (see below).

Statistical analysis. Our aim was to estimate typical frequencies of potentially productive and unproductive matings in sympatric populations of the Littorina (Neritrema) species. We defined potentially productive matings as matings with conspecific females and unproductive mating as matings with any other partners, with a caveat that matings with some heterospecific females could be productive. We assumed that a total effect of PMI could be due to a combination of several phenomena such as reproductive timing (differential mating activity of males), habitat-preference and adaptation, sexual selection and isolation, but not to differentially mating preferences or sexual selection per se, which require a different sampling design and use of other estimators ${ }^{47,48,52,65,66}$. Disentangling the effects of sexual selection and isolation can be very informative when applied to population studies, and their estimators have been developed (PSS and PSI ${ }^{52}$ ). When considering multiple species, however, sexual selection and isolation cannot be differentiated due to strong effects of e.g., habitat-preference, on observed mating pattern, the so-called "scale of choice" problem ${ }^{47,65,66}$. Therefore, in our study we focused on the total effects of all PMI mechanisms, including non-homogeneous spatial distribution, reproductive timing, and mechanisms of mate choice.

To test whether Littorina (Neritrema) males mate at random with any of the possible categories of passive partners, we modelled random mating (Table 1) where all the Neritrema snails available at a particular site and intertidal level were considered as potential passive partners, including males, females, or ITC individuals of all the five species. Since female periwinkles appear to play a passive role in mating ${ }^{29-31}$ and since there is no evidence that any potentially passive mates actively avoid copulation, we assumed that all individuals older than one year (identified by presence of the first annual growth ring on a shell) were potential partners (we have never observed younger individuals in copulation). Under the null hypothesis of random mating, the probability of being a passive partner in copulation is equal among snails at a particular site and intertidal level. Therefore, frequencies of potential passive partners corresponded to the ratio of respective categories in the populations, which were estimated from the same $0.04 \mathrm{~m}^{2}$ quadrats that were used to assess Littorina species composition.

In periwinkles, males are the active partners making copulation attempts ${ }^{29-32}$. Obviously, males of different species may differ in the degree of copulative activity for various reasons (e.g. not all mature males may be ready for copulation at a given time and their fraction in each species may vary). This is why we calculated frequencies 


\begin{tabular}{|c|c|c|c|c|}
\hline & & \multicolumn{3}{|c|}{$\begin{array}{l}\text { Passive partners (expected frequencies from population } \\
\text { frequencies) }\end{array}$} \\
\hline & & $A^{\prime}$ & B' & $\mathbf{C}^{\prime}$ \\
\hline \multicolumn{2}{|c|}{ Active male partners (expected frequencies from copulating pairs) } & $P_{A^{\prime}}=A^{\prime} /\left(A^{\prime}+B^{\prime}+C^{\prime}\right)$ & $P_{B^{\prime}}=B^{\prime} /\left(A^{\prime}+B^{\prime}+C^{\prime}\right)$ & $P_{C^{\prime}}=B^{\prime} /\left(A^{\prime}+B^{\prime}+C^{\prime}\right)$ \\
\hline $\mathrm{a}$ & $P_{a}=a /(a+b)$ & $S_{a A^{\prime}}=P_{a} P_{A^{\prime}} t$ & $S_{a B^{\prime}}=P_{a} P_{B^{\prime}} t$ & $S_{a C^{\prime}}=P_{a} P_{C^{\prime}} t$ \\
\hline $\mathrm{b}$ & $P_{b}=b /(a+b)$ & $S_{b A^{\prime}}=P_{b} P_{A^{\prime}} t$ & $S_{b B^{\prime}}=P_{b} P_{B^{\prime}} t$ & $S_{b C^{\prime}}=P_{b} P_{C^{\prime}} t$ \\
\hline
\end{tabular}

Table 1. Calculation of expected frequencies in the mating model used in the study. The process is illustrated with two types of active three types of passive partners; the same logic applies to a different number of partner types. $A^{\prime}, B^{\prime}, C^{\prime}$ - the number of passive partners of the types studied, counted from the population frequencies. $P_{A^{\prime}}, P_{B^{\prime}}, P_{C^{\prime}}$-probability to be a passive partner in copulation, estimated from the numbers in the population. $\mathrm{a}, \mathrm{b}-$ numbers of active male partners of the types studied, counted from copulating pairs. $P_{a} P_{b}-$ probability of copulation for a given type of active male partner, estimated form the frequency of this type of partner in copulating pairs. $t=a A^{\prime}+a B^{\prime}+a C^{\prime}+b A^{\prime}+b B^{\prime}+b C^{\prime}$-total observed number of copulating pairs. $S_{a A^{\prime}}, S_{b A^{\prime}}, S_{a B^{\prime}}$, $S_{b B^{\prime}}, S_{a C^{\prime}}, S_{b C^{\prime}}$-the expected number of pairs in each combination of partners.

of active partners based on their ratio in detected copulating pairs. Finally, the expected number of copulating pairs was calculated as the product of frequencies of potential passive partners, frequencies of active partners, and the total number of observed mating pairs (Table 1). This design does not correspond to any published estimators.

Our model of random mating does not take into account any possible habitat preference/adaptation barriers or spatio-temporal activity patterns (while the differences in microbiotope preferences between species do exist $^{28}$ ). Nevertheless, it estimates a hypothetical chance of males meeting partners of different species/status.

Possible combinations of partner types in copulating pairs. We listed all the possible passive partner types that can mate with males of each of the species of the subgenus Neritrema, as well as all possible active partner types that can mate with different types of passive partners. A combination of partner types was recorded as present if it appeared with non-zero observed frequency among all registered mating pairs. The information on presence/absence of observed combinations of partner types was arranged in a table, with types of active partners in columns and types of passive partners in rows (see the subsection (1) General description of copulatory activity in the Results section). Pairwise differences in the lists of observed combinations of partner types were evaluated separately for types of active mates (columns) and types of passive mates (rows) using simple mismatch coefficient ${ }^{67}$ (SMC). SMC is a distance measure that corresponds to the simple matching coefficient, which is the conventional similarity measure for binary data ${ }^{68}$. SMC between the lists of possible passive partner types of active partners of types $i$ and $j$ is calculated as $S M C_{(i, j)}=\frac{f_{10}+f_{01}}{f_{11}+f_{10}+f_{01}+f_{00}}$, where $f_{10}$ is the number of distinct passive partner types that were observed mating with active males of type $i$, but not with $j$; $f_{01}$-were observed mating with active males of type $j$, but not with $i ; f_{00}$-were not observed mating with either types of active partners, $f_{11}$-were observed mating with the both types of active partners. SMC between the lists of possible active partner types of passive partners was calculated in the same way. The two resulting symmetric distance matrices were clustered using Unweighted Pair Group Method with Arithmetic Mean (UPGMA) and plotted using dendextend package ${ }^{69}$ in $\mathrm{R}^{70,71}$.

Fidelity Index (FI) was proposed to measure the prevalence of heterosexual mating with conspecific partners (potentially productive matings) over mating with other types of partners (potentially unproductive ones) compared to the null expectation of random mating. It was calculated as a difference between the observed and the expected numbers of copulations with conspecific partners, divided by the sum of expected numbers of all copulations. For example, following the notation defined in Table 1, $F I_{a A^{\prime}}=\frac{a A^{\prime}-S a A^{\prime}}{S_{a A^{\prime}}+S_{a B^{\prime}}+S_{a C^{\prime}}}$ is the fidelity of males of type $a$ to conspecific females $A^{\prime}$ (the difference of observed and expected frequencies of mating of males of type $a$ with conspecific females $A^{\prime}$ is divided by the sum of expected frequencies of copulation of males of type $a$ with conspecific and all heterospecific females). The possible values of fidelity index range from -1 to 1 ( $-1=$ avoidance, $0=$ random mating, 1 =assortative mating). The index was calculated for males and females of each species within each year/site $\times$ level combination. Bootstrap with 10000 iterations was used to calculate mean bootstrap values, standard deviations, and the two-tail probability of rejecting the null hypothesis of random mating $\left(\mathrm{H}_{0}\right.$ : $\mathrm{FI}=0)$.

Ordination in the space of sexual partners. Patterns of copulation in the species studied were described using partial Canonical Correspondence Analysis ${ }^{53,54,72}$ (pCCA) using vegan package ${ }^{73}$. pCCA is a $\chi^{2}$-based multivariate approach. This method has a certain advantage over traditional univariate methods of mating pattern analysis, because it allows one to visualise and compare multiple categories of partners simultaneously as a whole system. Thus, pCCA allows one to avoid multiple comparisons of mating frequencies. In addition, pCCa permits evaluation of possible deviation of observed frequencies from the frequencies expected under the null hypothesis, after removing the effect of background factors such as site and intertidal level, thus highlighting common and general patterns.

The observed copulation frequencies were arranged in a table with passive partners in rows and active partners in columns. Expected copulation frequencies for pCCA were calculated as described above, based on species- and sex-composition, and frequency of copulating males. In the pCCA procedure, the effect of the type of passive partner (combination of species and sex) was tested after removing the variation explained by the covariate 
(combination of site and year). Due to different species composition two separate analyses were performed on the data from the upper (157 pairs) and lower intertidal levels (149 pairs). Several categories of passive copulants (males of L. arcana and L. saxatilis with 1.5 rows of penial glands, and immature "saxatilis" snails) were excluded from the analysis of the data from the lower level in Kiberg in 2016 because these categories were absent in the field samples and so their expected mating frequencies could not be calculated. The effect of passive partner type on copulation frequencies was tested using Monte Carlo procedure with 10000 permutations, restricted within strata defined by sampling site and year. The percentage of variance explained by each axis was obtained by dividing the canonical eigenvalues by the total inertia.

Degree of disassortative mating between pairs of Littorina species was assessed at each year/site and intertidal level using the precopulatory isolation index $\mathrm{I}_{\mathrm{PC}}$. $\mathrm{I}_{\mathrm{PC}}$ was computed as a joint isolation index ${ }^{51,74}$, except that the ratios of observed to expected frequencies of specific copulation types were used instead of raw counts. The ratios were also used when calculating $\mathrm{I}_{\mathrm{PSI}}$, a metric proposed by Rolán-Alvarez \& Caballero ${ }^{52}$. Previous research has shown that basing calculations on the ratios rather than the raw counts improves the statistical properties of isolation metrics ${ }^{52,75}$. Our metric $\left(\mathrm{I}_{\mathrm{PC}}\right)$ differs from $\mathrm{I}_{\mathrm{PSI}}$, however, in that it estimates the combined effect of precopulatory isolation (i.e. sexual isolation and sexual selection) because the expected frequencies are calculated using both the composition and pairing frequencies, obtained from the null model of copulation described above, within each population. The value of $\mathrm{I}_{\mathrm{PC}}$ varies between -1 and 1 , where -1 indicates disassortative mating, $0=$ random mating, and $1=$ assortative mating. Only copulations with mature females were used for the analysis. L. saxatilis males with 1.5 rows of penial glands were excluded. Mean bootstrap values, standard deviations, and the two-tail probability of rejecting the null hypothesis of random mating $\left(\mathrm{H}_{0}: \mathrm{I}_{\mathrm{PC}}=0\right)$ were calculated using bootstrap with 10000 iterations.

The effect of shell size on mating patterns. Shell size of mating and non-mating individuals was summarized on boxplots to examine distribution of sizes. Kernel density plots were used to visualize overlap of the size-distributions of mating and non-mating snails.

Mean differences of partner shell sizes in heterosexual pairs (with con- or heterospecific females, and ITC individuals) were analysed to reveal any tendencies to mate with partners of a certain size. Size differences between partners were tested using paired $t$-test separately for each active partner species, year/site, and intertidal level (where $\geq 5$ pairs were available).

Interdependence of partner shell sizes in all heterosexual pairs of L. saxatilis from the upper level (where the sample size was sufficient) was tested using a full-factorial 3-way permutational Analysis of Covariance (ANCOVA) in lmPerm package ${ }^{76}$. Active partner size was a response, and passive partner size, pair type (samespecies $v s$ other), year/site, and their interactions were used as predictors. Type III tests ${ }^{77}$ were run with 100000 permutations.

Correlation of partner shell sizes in pairs with mature conspecific females was computed for L. saxatilis, L. obtusata and L. fabalis to test a possible importance of size in mate choice. Calculations were performed separately for different year/sites and intertidal levels. A test with 10000 permutations was used to assess significance. To find out whether correlation of partner sizes in pairs with mature conspecific females could be a consequence of random mating within microareas (e.g. sample squares), a Monte Carlo simulation was performed. Random pairs of males with mature conspecific females were simulated from each of the quadrats and correlation of their sizes was computed. This procedure was repeated 10000 times. $P$-value (the proportion of correlation coefficients with an absolute value greater or equal to the observed value) in this test can be interpreted as the probability to get correlation this strong when snails mate at random within the sample squares. To assess spatial segregation by size (another possible cause of correlation of partner sizes in the pairs with mature conspecific females), a permutation test was performed for $L$. saxatilis and L. obtusata, for which enough data were available. Analysis was performed separately for different year/sites and intertidal levels, following the procedure adapted from Erlandsson and Johannesson ${ }^{39}$. Snails were divided into two size groups: small and large relative to local median shell height. Small snails were assigned rank 0 while large snails - rank 1 . The variance of ranks was calculated for each sample, and the mean variance of ranks was the test statistic. Data on the number of small and large snails were permuted 10000 times to compute the empirical distribution of average variance. Low observed mean variance would indicate spatial segregation by size. $P$-values were computed as a fraction of permutations that produced lower mean variance than the originally observed value. Plots were produced using ggplot 2 package ${ }^{78}$.

\section{Results}

General description of copulatory activity. In total, 317 copulating pairs of five Littorina species were collected from two collection sites at the Barents Sea coast during three summer seasons. Most of the copulating snails were identified as L. saxatilis and L. obtusata ( $43 \%$ and $22 \%$ of all copulating snails; Supplement S5). This was not surprising because those species were the most abundant in the study sites (Supplement S3).

The proportion of unproductive copulations was different between the species groups. Among all the recorded copulations, $60 \%$ were productive (191 pairs with conspecific female) and 40\% were unproductive (19 [6\%] with heterospecific females; 59 [19\%] with conspecific or heterospecific males; and 48 [15\%] with ITC individuals (Table 2). Interestingly, males of the "saxatilis" group were involved in potentially unproductive mating far more often (109 of 206 pairs, 53\%) than those of the "obtusata" group (24 of 111 pairs, 22\%) (Table 2), though the sex ratio in both species-groups in all analysed populations was roughly the same (Supplement S3).

Males and females were recognized by their partners with a different accuracy. Not all possible combinations were detected. For example, there were no registered pairs of any males of "saxatilis" group with L. obtusata females, and vice versa, no pairs of L. obtusata males with any of the "saxatilis" group females, implying the reliability of premating barriers. At the same time, heterospecific male-male copulations were detected in all 


\begin{tabular}{|c|c|c|c|c|c|c|c|}
\hline Site & Level & $\begin{array}{l}\text { Active male } \\
\text { species }\end{array}$ & Total & $\begin{array}{l}\text { Conspecific } \\
\text { female }\end{array}$ & $\begin{array}{l}\text { Heterospecific } \\
\text { female }\end{array}$ & $\begin{array}{l}\text { Immature or } \\
\text { castrated }\end{array}$ & $\begin{array}{l}\text { Male (any } \\
\text { species) }\end{array}$ \\
\hline \multirow{8}{*}{ D. Zelentsy, 2015} & \multirow{3}{*}{ Upper } & L. saxatilis & 63.5 & $41(64.6)$ & & $10(15.7)$ & $12.5(19.7)$ \\
\hline & & $\begin{array}{l}\text { L. saxatilis (1,5 } \\
\text { row) }\end{array}$ & 12.5 & $6(48)$ & & $1(8)$ & $5.5(44)$ \\
\hline & & L. arcana & 15 & & $7(46.7)$ & $2(13.3)$ & $6(40)$ \\
\hline & \multirow{5}{*}{ Lower } & L. saxatilis & 17 & $10(58.8)$ & $1(5.9)$ & $4(23.5)$ & $2(11.8)$ \\
\hline & & L. arcana & 2.5 & & $2(80)$ & & $0.5(20)$ \\
\hline & & L. compressa & 3 & $3(100)$ & & & \\
\hline & & L. obtusata & 23.5 & $19(80.9)$ & & & $4.5(19.1)$ \\
\hline & & L. fabalis & 2 & $1(50)$ & $1(50)$ & & \\
\hline \multirow{9}{*}{ Kiberg, 2016} & \multirow{3}{*}{ Upper } & L. saxatilis & 21 & $13(61.9)$ & & $6(28.6)$ & $2(9.5)$ \\
\hline & & $\begin{array}{l}\text { L. saxatilis (1,5 } \\
\text { row) }\end{array}$ & 3.5 & $2(57.1)$ & & $1(28.6)$ & $0.5(14.3)$ \\
\hline & & L. arcana & 1.5 & & & & $1.5(100)$ \\
\hline & \multirow{6}{*}{ Lower } & L. saxatilis & 17.5 & $9(51.4)$ & & $5(28.6)$ & $3.5(20)$ \\
\hline & & $\begin{array}{l}\begin{array}{l}\text { L. saxatilis (1,5 } \\
\text { row) }\end{array}\end{array}$ & 7 & $4(57.1)$ & & $2(28.6)$ & $1(14.3)$ \\
\hline & & L. arcana & 4 & & $2(50)$ & $1(25)$ & $1(25)$ \\
\hline & & L. compressa & 1.5 & $1(66.7)$ & & & $0.5(33.3)$ \\
\hline & & L. obtusata & 29 & 27 (93.1) & & & $2(6.9)$ \\
\hline & & L. fabalis & 4 & $2(50)$ & $1(25)$ & $1(25)$ & \\
\hline \multirow{8}{*}{ Kiberg, 2017} & \multirow{4}{*}{ Upper } & L. saxatilis & 22 & $8(36.4)$ & $2(9.1)$ & $8(36.4)$ & $4(18.2)$ \\
\hline & & $\begin{array}{l}\text { L. saxatilis (1,5 } \\
\text { row) }\end{array}$ & 3.5 & $1(28.6)$ & & $2(57.1)$ & $0.5(14.3)$ \\
\hline & & L. arcana & 2 & $1(50)$ & $1(50)$ & & \\
\hline & & L. obtusata & 12.5 & $7(56)$ & & $1(8)$ & $4.5(36)$ \\
\hline & \multirow{4}{*}{ Lower } & L. saxatilis & 4 & $1(25)$ & $1(25)$ & & $2(50)$ \\
\hline & & L. compressa & 5 & $4(80)$ & & & $1(20)$ \\
\hline & & L. obtusata & 22 & $17(77.3)$ & & $1(4.5)$ & $4(18.2)$ \\
\hline & & L. fabalis & 18 & $14(77.8)$ & $1(5.6)$ & $3(16.7)$ & \\
\hline
\end{tabular}

Table 2. Mating patterns of active male Littorina snails grouped by site, intertidal level and species. Total number of copulations of a particular active partner type, as well as the number (and percentage) of copulations grouped by passive partner category is given. Male-male copulations were registered as 0.5 for each of the partners, because it was impossible to determine which of them was active. The category L. saxatilis (1.5 row) includes male L. saxatilis with 1.5 rows of penial glands (presumably hybrids of L. saxatilis and L. arcana); both $L$. saxatilis and L. arcana females were considered their conspecifics. Empty table cells indicate that corresponding mating combinations were not detected.

possible combinations (L. arcana + L. obtusata, L. compressa + L. obtusata, L. saxatilis + L. obtusata, Table 3). These differences in accuracy of male- or female-recognition may be explained by different cues involved in setting off copulation attempts with males and females. This agrees with the observation that among $210(66 \%)$ male-female pairs only 19 (9\%) pairs were between heterospecifics, while among 59 (19\%) male-male pairs, there were $14(24 \%)$ heterospecific pairs. A possible interpretation is that a male recognizes the species of a passive partner more accurately when mating with a female. This is consistent with the generally closer ordination of males and ITC to the origin compared to females on CCA-plots (Supplement S8). However, it is applicable not to all the species studied as no male-male pairs, either con- or heterospecific, were registered in case of $L$. fabalis.

Mating patterns of $L$. compressa were different from its close relatives L. saxatilis and L. arcana. Individuals of L. saxatilis and L. arcana were encountered in similar mating combinations, both as active and passive partners, as evidenced by their close grouping on the dendrograms (Fig. 3, Table 3). L. compressa grouped with L. obtusata and L. fabalis (Fig. 3) and appeared reproductively isolated from the two other species of the "saxatilis" group: active males of $L$. compressa did not mate with either passive adults of L. saxatilis and L. arcana or with ITC "saxatilis" snails (all these categories co-occurred with L. compressa in the populations), while passive individuals of $L$. compressa mated only with conspecifics or with $L$. saxatilis out of all the species of the "saxatilis" group (Table 3). Mating combinations within the L. compressa, L. fabalis, L. obtusata cluster were more dissimilar than within the L. saxatilis and L. arcana cluster (Fig. 3), which also indicates a strong reproductive isolation within the former cluster.

Prevalence of copulations with conspecific females. The FI was calculated for males of each species (as choosing partners, see above) to assess the degree of the mate choice accuracy (the prevalence of matings with conspecific females). The lower the FI value, the more often males of a particular species commence potentially unproductive copulation attempts. Similarly, this index was calculated for the females to find out how 


\begin{tabular}{|c|c|c|c|c|c|c|}
\hline \multirow[b]{2}{*}{ Passive partner } & \multicolumn{6}{|c|}{ Active partner } \\
\hline & L. saxatilis & L. saxatilis 1.5 row & L. arcana & L. compressa & L. obtusata & L. fabalis \\
\hline L. saxatilis female & + & + & + & - & - & + \\
\hline L. saxatilis male & + & + & + & - & + & - \\
\hline L. saxatilis male (1.5 row) & + & + & + & - & - & - \\
\hline L. arcana female & + & - & + & - & - & - \\
\hline L. arcana male & + & + & + & - & + & - \\
\hline L. compressa female & + & - & - & + & - & - \\
\hline L. compressa male & - & - & - & + & + & - \\
\hline L. obtusata female & - & - & - & - & + & + \\
\hline L. obtusata male & + & - & + & + & + & - \\
\hline L. fabalis female & + & - & - & - & - & + \\
\hline 'saxatilis' & + & + & + & - & - & - \\
\hline 'obtusata' & - & - & - & - & + & + \\
\hline
\end{tabular}

Table 3. Observed combinations of partner types in mating pairs. The category L. saxatilis (1.5 row) includes male L. saxatilis with 1.5 rows of penial glands (presumably hybrids of L. saxatilis and L. arcana). The categories "obtusata" and "saxatilis" include immature or castrated individuals of the corresponding cryptic species group.

A
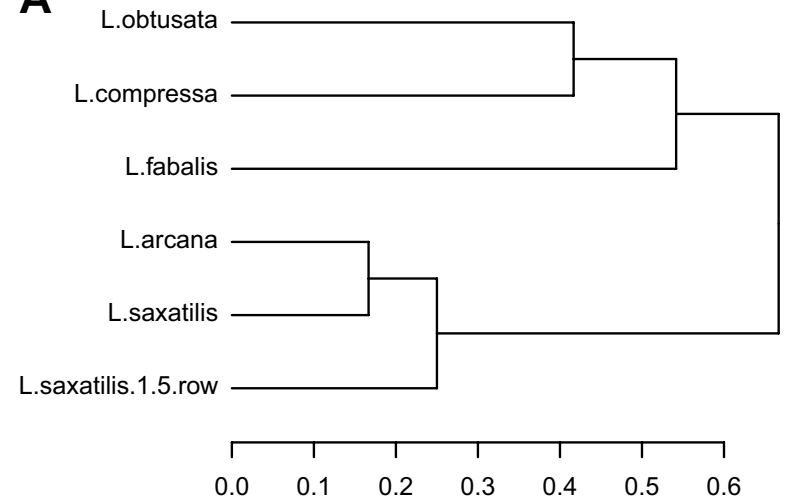

Binary data, Simple mismatch coefficient, UPGMA
B

'obtusata'

L.obtusata f

L.fabalis $f$

L.compressa $\mathrm{m}$

L.compressa $f$

L.obtusata $\mathrm{m}$

'saxatilis'

L.saxatilis $\mathrm{m}(1.5 \mathrm{row})$

L.saxatils

L.arcana $\mathrm{m}$

L.saxatilis $\mathrm{m}$

L.arcana $f$

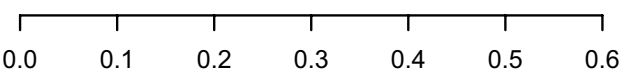

Binary data, Simple mismatch coefficient, UPGMA

Figure 3. Clustering of observed combinations of partner types. Distances indicate dissimilarity of the lists of all observed partner types for active (A) and passive (B) mates (simple mismatch coefficient; Mirkin, 1996). The category L. saxatilis (1.5 row) includes L. saxatilis males with 1.5 rows of penial glands (presumably hybrids of L. saxatilis and L. arcana). The categories "obtusata" and "saxatilis" include immature or castrated individuals of the corresponding cryptic species group.

frequently they were engaged by conspecific males (Supplement S7). On average, the FI values of the "obtusata" group males exceeded those of L. saxatilis and especially L. arcana (Table 4, Supplement S7), whereas males of L. compressa demonstrated the highest fidelity among all the five species (Table 4) and the lowest rate of unproductive mating ( $16 \%$; Table 2 ). However, these estimates should be treated with caution due to the comparatively low number of pairs analysed (11).

Ordination in the space of sexual partners. Partial canonical correspondence analysis (pCCA, Supplement S8) was applied to evaluate a possible deviation of observed mating frequencies from the ones expected under the assumption of random mating (calculated based on species- and sex-ratio in the natural populations). The pCCA ordination of passive and active partners generally confirmed the tendencies outlined above. Firstly, the mating frequencies of female passive partners differed more strongly from the random pattern than the mating patterns of the other categories. Secondly, L. obtusata, L. fabalis and L. compressa males were clearly attracted to conspecific females.

Littorina obtusata was reliably isolated from both the species of the "saxatilis" group and from L. fabalis. This was confirmed by pCCA ordination (Supplement S8) and by a high value of the isolation index within the "obtusata" group (0.88 and 0.99 in Kiberg in 2016 and 2017, respectively; Table 5). L. obtusata males showed 


\begin{tabular}{|l|l|r|r|l|}
\hline Species & Level & D. Zelentsy, 2015 & \multicolumn{1}{l|}{ Kiberg, 2016 } & Kiberg, 2017 \\
\hline \multirow{2}{*}{ L. saxatilis } & Upper & $0.48 \pm 0.06, \mathrm{p}<0.001$ & $0.51 \pm 0.11, \mathrm{p}<0.001$ & $0.27 \pm 0.11, \mathrm{p}=0.005$ \\
\cline { 2 - 5 } & Lower & $0.48 \pm 0.13, \mathrm{p}<0.001$ & $0.45 \pm 0.13, \mathrm{p}<0.001$ & $0.18 \pm 0.22, \mathrm{p}=0.780$ \\
\hline \multirow{2}{*}{ L. arcana } & Upper & $-0.04 \pm 0.02, \mathrm{p}=0.183$ & $0.03 \pm 0.16, \mathrm{p}=0.204$ & $0.34 \pm 0.34, \mathrm{p}=0.680$ \\
\cline { 2 - 5 } & Lower & $0.03 \pm 0.11, \mathrm{p}=0.182$ & $-0.01 \pm 0.07, \mathrm{p}=0.173$ & \\
\hline L. compressa & Lower & $0.62 \pm 0.27, \mathrm{p}=0.066$ & $0.37 \pm 0.35, \mathrm{p}=0.692$ & $0.67 \pm 0.22, \mathrm{p}=0.035$ \\
\hline \multirow{2}{*}{ L. obtusata } & Upper & & & $0.48 \pm 0.15, \mathrm{p}=0.002$ \\
\cline { 2 - 5 } & Lower & $0.71 \pm 0.09, \mathrm{p}<0.001$ & $0.52 \pm 0.08, \mathrm{p}<0.001$ & $0.38 \pm 0.11, \mathrm{p}=0.005$ \\
\hline L. fabalis & Lower & & $0.38 \pm 0.26, \mathrm{p}=0.306$ & $0.73 \pm 0.11, \mathrm{p}<0.001$ \\
\hline
\end{tabular}

Table 4. Fidelity index (FI) of male Littorina snails grouped by species, intertidal level and year/site. FI measures prevalence of mating of males with conspecific females. It is computed as difference of observed and expected numbers of heterosexual conspecific copulations with males of a given species, divided by the total number of copulations with males of that species. Values of FI vary from - 1-avoidance, through 0 -random mating, to 1 -assortative mating. FI was not computed for $L$. saxatilis males with 1.5 rows of penial glands. Bootstrap means \pm standard deviations are given; $p$-the two-tail probability of rejecting $\mathrm{H}_{0}: \mathrm{FI}=0$ in the test using bootstrap with 10000 iterations.

\begin{tabular}{|c|c|c|c|c|c|}
\hline Comparison & Species & Level & D. Zelentsy, 2015 & Kiberg, 2016 & Kiberg, 2017 \\
\hline \multirow{4}{*}{ Within "saxatilis" group } & \multirow{2}{*}{ L. saxatilis-L. arcana } & Upper & $0.19 \pm 0.21, \mathrm{p}=0.377$ & $0.86 \pm 0.34, p=0.14$ & $0.26 \pm 0.52, \mathrm{p}=0.605$ \\
\hline & & Lower & $0.03 \pm 0.54, \mathrm{p}=0.879$ & $-0.14 \pm 0.54, p=0.541$ & \\
\hline & L. saxatilis-L. compressa & Lower & $0.89 \pm 0.16, p=0.003$ & $0.91 \pm 0.26, p=0.066$ & $0.94 \pm 0.19, p=0.012$ \\
\hline & L. arcana-L. compressa & Lower & $0.78 \pm 0.55, p=0.199$ & $0.72 \pm 0.6, p=0.214$ & \\
\hline Within "obtusata" group & L. obtusata-L. fabalis & Lower & & $0.88 \pm 0.21, \mathrm{p}=0.023$ & $0.99 \pm 0.04, \mathrm{p}<0.001$ \\
\hline \multirow{8}{*}{ Between groups } & \multirow{2}{*}{ L. obtusata-L. saxatilis } & Upper & & & $0.98 \pm 0.06, \mathrm{p}<0.001$ \\
\hline & & Lower & $0.99 \pm 0.03, \mathrm{p}<0.001$ & $0.99 \pm 0.04, \mathrm{p}<0.001$ & $0.92 \pm 0.23, p=0.058$ \\
\hline & \multirow{2}{*}{ L. obtusata-L. arcana } & Upper & & & $0.92 \pm 0.23, p=0.036$ \\
\hline & & Lower & $0.86 \pm 0.34, \mathrm{p}=0.112$ & $0.9 \pm 0.25, \mathrm{p}=0.015$ & \\
\hline & L. obtusata-L. compressa & Lower & $0.95 \pm 0.14, \mathrm{p}<0.001$ & $0.92 \pm 0.24, \mathrm{p}=0.029$ & $0.98 \pm 0.09, p=0.004$ \\
\hline & L. fabalis-L. Saxatilis & Lower & & $0.95 \pm 0.14, \mathrm{p}=0.004$ & $0.58 \pm 0.34, p=0.096$ \\
\hline & L. fabalis-L. arcana & Lower & & $0.83 \pm 0.42, \mathrm{p}=0.128$ & \\
\hline & L. fabalis-L. compressa & Lower & & $0.86 \pm 0.35, \mathrm{p}=0.091$ & $0.97 \pm 0.07, \mathrm{p}<0.001$ \\
\hline
\end{tabular}

Table 5. Precopulatory Isolation Index within and between Littorina "saxatilis" and "obtusata" species categorized by site and littoral zone. $\mathrm{I}_{\mathrm{PC}}$ describes total premating isolation; its value varies between -1 and 1 (- 1-disassortative mating, 0 -random mating, 1-assortative mating). L. saxatilis males with 1.5 penial rows were excluded from the analysis. Bootstrap means \pm standard deviations are given; $p$ - the two-tail probability of rejecting $\mathrm{H}_{0}$ : $\mathrm{I}_{\mathrm{PC}}=0$ in the test using bootstrap with 10000 iterations.

preferential mating with conspecific females and with conspecific males, the latter being evident in the upper littoral zone.

Males of L. fabalis apparently preferentially mated with conspecific females (Supplement S8), which corresponds to a high FI value of these males and a significant precopulatory isolation within the "obtusata" group (Table 5).

In the "saxatilis" group, males of $L$. compressa had a high FI value (Table 4) and were attracted to conspecifics according to pCCA results (Supplement S8). Although members of the "saxatilis" group in general showed low or non-significant $\mathrm{I}_{\mathrm{PC}}$ values, on two occasions precopulatory isolation between L. compressa males and L. saxatilis was significant (Table 5).

A peculiar mating pattern was found in the species pair L. arcana + L. saxatilis. Three categories of active partners were taken into account: L. saxatilis (1 row of penial glands), L. arcana (2 and more rows of penial glands) and 1.5 rows-males (presumably hybrids between L. saxatilis and L. arcana; for details see Methods section and ${ }^{59}$ ). Males of all the three categories exhibited a similar pattern of copulatory activity, being most often found in pairs with L. saxatilis females. This is why these three categories of males grouped very closely on pCCA biplots in both the upper and the lower intertidal (Fig. 4). While L. saxatilis males had moderately high FI values (Table 4), L. arcana males had negative FI values in four of the five cases, which implies more rare pairing with conspecific females than expected based on random encounters. Actually, out of the 13 pairs of L. arcana males with mature females, 12 were with $L$. saxatilis females and only one with $L$. arcana female. Similarly, males of L. saxatilis were mainly recorded in pairs with females of $L$. saxatilis, (82 of 86 pairs) and only rarely with females of the other species ( 2 pairs with $L$. arcana, 1 with $L$. compressa, 1 with $L$. fabalis; Table 2 ). The FI values for 


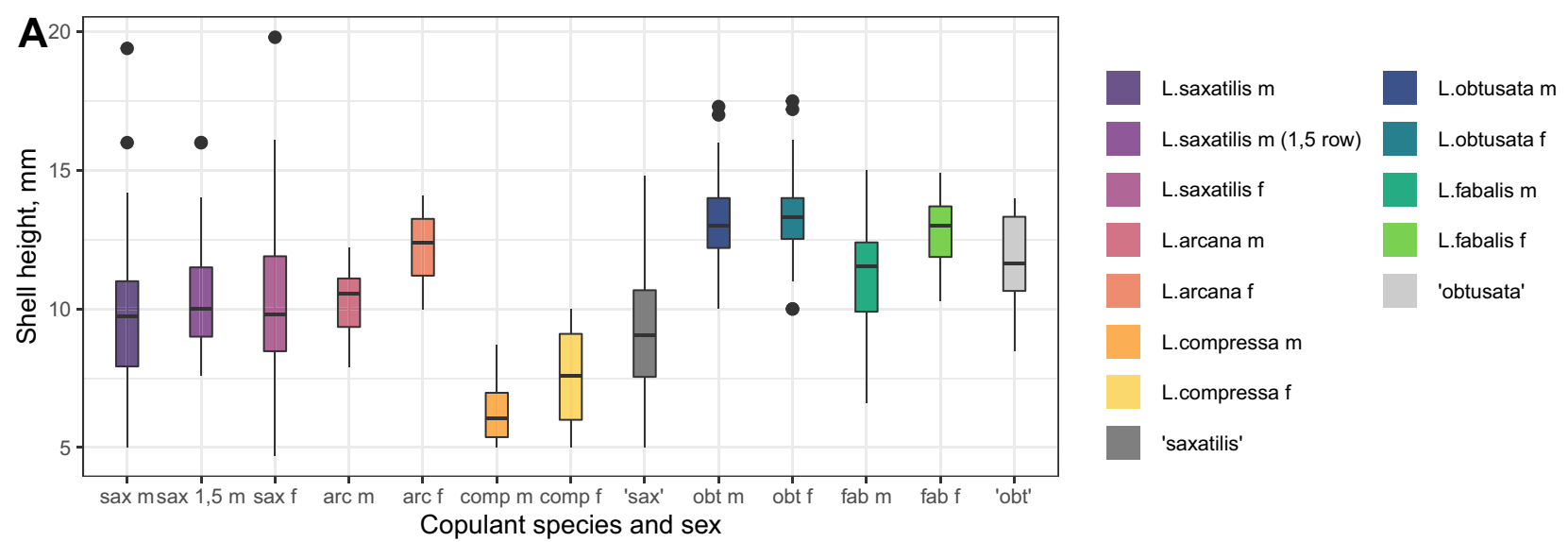

B L.saxatilis males vs. others, D.Zelentsy 2015, lower shore

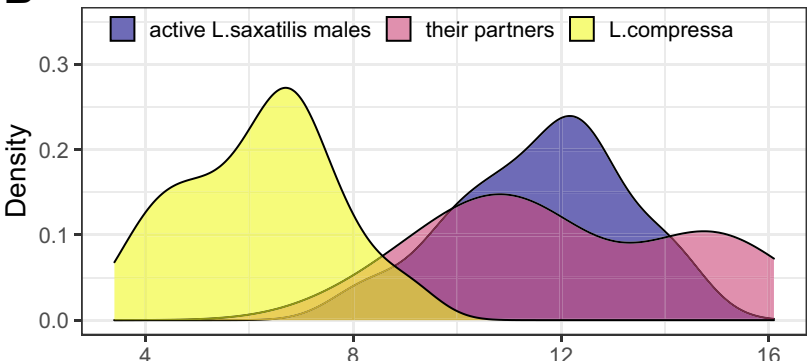

L.obtusata males vs. others, Kiberg 2016, lower shore

L.fabalis males vs. others, Kiberg 2017, lower shore
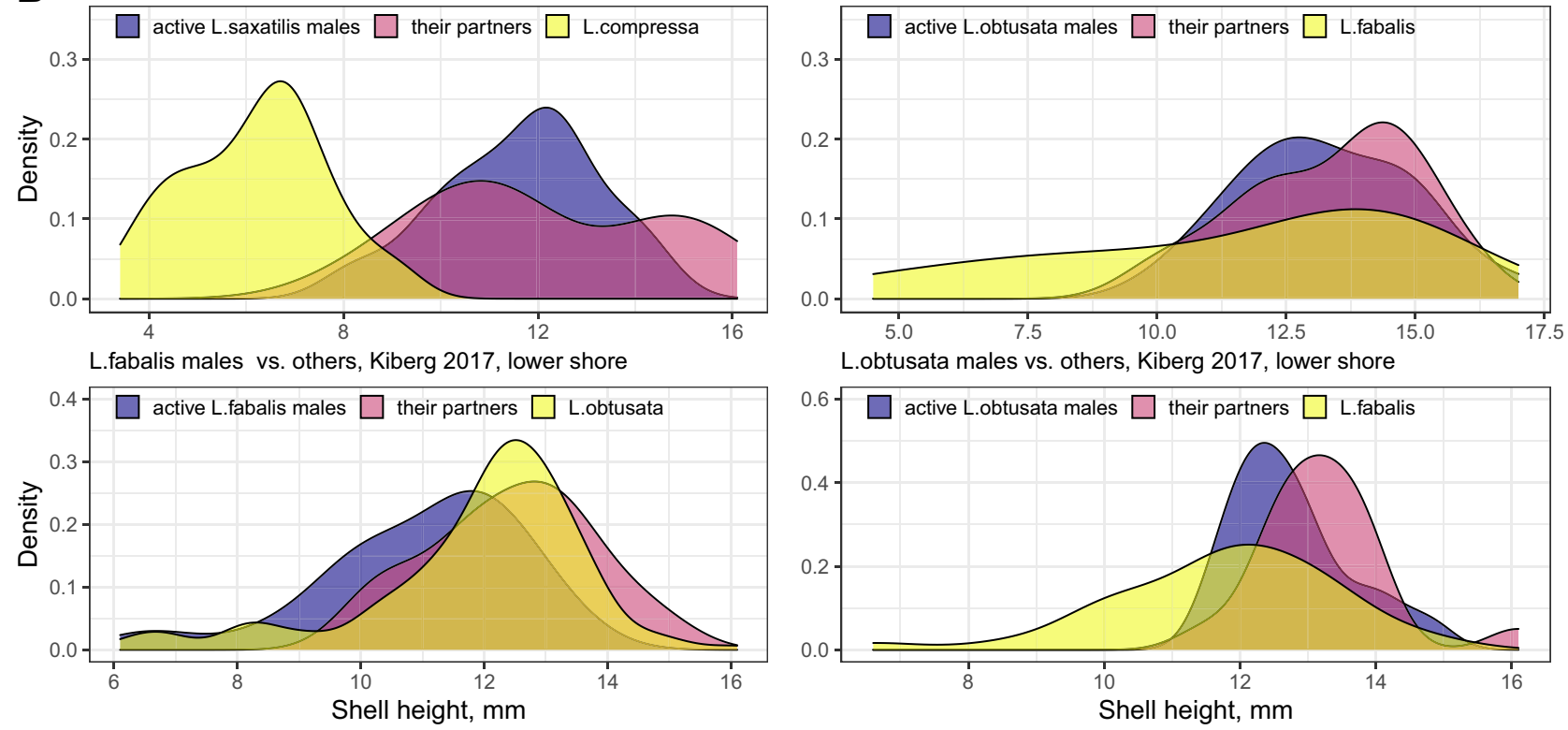

L.obtusata males vs. others, Kiberg 2017, lower shore

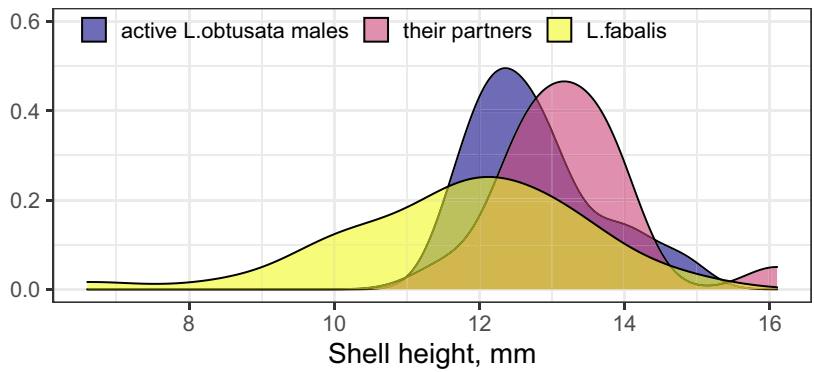

Figure 4. Shell height of copulating Littorina snails. Male-male pairs were excluded from the analysis. (A) All partners categorized by sex and species; data from different sites and levels were pooled. Dots indicate the values less or greater than 1.5 interquartile ranges from the median. (B) Shell height distributions illustrating potential for isolation by size in L. saxatilis vs L. compressa, L. obtusata vs L. fabalis (and vice versa); copulating males of the first species (violet), their passive partners (magenta, male-male pairs were excluded), and all collected individuals of the second species (yellow). All data on the size of mating and non-mating snails can be found in Supplement S9.

males with 1.5 penial rows could not be calculated because their species was uncertain. Nevertheless, all the 13 heterosexual copulations with mature individuals, registered for these males, involved L. saxatilis females only (Table 2). This unexpected "neglect" of L. arcana females by conspecifics as well as other species determined the low values of $\mathrm{I}_{\mathrm{PC}}$ from the other species of the "saxatilis" group (Table 5).

The effect of shell size on copulation. The size of copulating snails was compared to the size distribution in the field samples to test the randomness or assortative mating. The size may explain some of the copulatory patterns in the populations studied. Despite a considerable overlap of size ranges, both active and passive copulating snails of different species differed in their mean size (Fig. 4; Supplements S9-S14). For example, copulating individuals of $L$. fabalis and L. obtusata were on average larger than those of the species of the "saxatilis" group; copulating L. obtusata were usually slightly larger than L. fabalis; copulating L. arcana and L. saxatilis apparently exceeded L. compressa in size. The overlap in the latter case was rather low (Fig. 4B), suggesting that a mismatch in size might contribute to the reproductive isolation of at least L. compressa from L. saxatilis and L. arcana.

Males copulating with ITC individuals were on average smaller than those copulating with mature females (Supplement S11). This tendency was apparent for L. saxatilis and for L. fabalis. In heterosexual pairs of L. fabalis and L. saxatilis with 1.5 penial rows, the male was significantly smaller than its female mate (Supplement S14).

A significant correlation of partner sizes was observed for pairs involving $L$. saxatilis males, when the pairs with conspecific females and with other partners (heterospecific females or ITC individuals) were analysed 
together (Supplement S15). Some other tendencies related to roles of the shell size in the mating activity of the snails can be found in Supplements S9-S16.

\section{Discussion}

In this study, we analysed natural mating activity in populations of five closely related periwinkle species $L$. arcana, L. compressa, L. saxatilis, L. fabalis and L. obtusata, living in sympatry in a large part of their European distribution. These species demonstrate a pronounced seasonality of reproduction in the Northern part of their distribution, with breeding seasons overlapping between the species ${ }^{33,55-57}$. We used the composition and frequencies of copulating pairs as a proxy for the description of the mating pattern and PMI strength. As expected for sympatric species, we observed that mating activity deviated significantly from the null hypothesis of random mating, which implies that interspecies PMI does function. However, the species varied in the efficacy of interspecies PMI. Below we hypothesize about the possible mechanisms underlying these barriers and the variation of their strength. Interestingly, the females were recognized more accurately than males and ITC individuals as heterospecific heterosexual pairs were rare phenomenon while homosexual ones were not. We suggest that these potentially unproductive copulations may indicate the basal frequency of meetings between snails of different species, and thus to roughly demarcate the effects of habitat choice (potentially unproductive heterospecific matings) and mate choice (conspecific male-female matings). The correlation between the sizes of the mates was expected, but its magnitude differed across the species. Quite probably, in some species pairs, the differences in shell size of adult snails ensure reproductive isolation based on mate choice mechanisms. Nevertheless, considering the data on microhabitat preferences ${ }^{28}$, we suggest that the principal proximate mechanism of PMI in the sympatric species group studied is the habitat choice (including habitat-preference and habitat associated fitness isolation). This mechanism makes the strongest contribution, but can be complemented by others. This becomes evident when all types of naturally occurring pairs (with females, males, immature and castrated conand heterospecific individuals) are considered.

Both homo- and heterosexual copulations were registered in four of the five species. It has previously been shown that the heterosexual copulation lasts much longer than the homosexual one ${ }^{38,39}$. This can lead to an underestimation of the observed frequency of homosexual copulation ${ }^{38}$. Moreover, the duration of copulations with conspecific females depends on their size and shell shape ${ }^{38,50}$. On the other hand, snails engaged in shorter copulations have a chance to make more mating attempts. This means that these two factors are opposite. Thus, we assumed that the number of registered pairs in our study does reflect the frequencies of mating attempts of the males, which are the active sex in snails, while females are passive during copulation ${ }^{29-31}$.

Male-male mating phenomenon. Male-male pairs have been recorded fairly often in studies of mating activity of littorinids ${ }^{37,38,40,42,43,60}$. In some species, e.g. L. saxatilis, the rate of homosexual mating reached $30 \%{ }^{42}$, and a biological significance of this phenomenon was suggested ${ }^{38}$. Other littorinids, such as Nodilittorina hawaiiensis or Littoraria pintado, have never been detected in male-male pairs even when a large number of pairs were analysed ${ }^{79}$.

The species in our study varied significantly in their propensity to form male-male pairs (Table 2). The mean frequency of male-male copulation was about $16-18 \%$ in L. saxatilis, L. compressa and L. obtusata. It was much higher, up to $36 \%$, in L. arcana and presumably hybrid males (with 1.5 penial rows), while L. fabalis males were not found in homosexual pairs at all. This distinctiveness of $L$. fabalis was quite unexpected because males of both L. fabalis and L. obtusata were shown to discriminate the sex of passive partners by their mucus trails, while males L. saxatilis were not (Johannesson et al., 2010). Importantly, sexes of these species did not differ in shell shape ${ }^{28}$.

Premating isolation between the "saxatilis" and "obtusata" groups. Almost no potentially productive copulations were registered between members of different groups. This suggests that there is a reliable premating isolation between the "saxatilis" and the "obtusata" group of cryptic species. The rare exceptions were represented by sporadic L. fabalis/L. saxatilis pairs (in both directions). Quite possibly, the involvement of L. saxatilis into these pairs was associated merely with the fact that it was the most abundant "saxatilis" species. Interestingly, L. fabalis males were also collected in pairs with L. obtusata females, while L. obtusata males were not encountered with either L. saxatilis or L. fabalis females. In contrast, both L. obtusata and L. saxatilis males were collected in homosexual heterospecific (between-group) pairs, but the males of $L$. fabalis were not. This illustrates the differences in behavioural biology between these species (see below).

Premating isolation within the "obtusata" group. The pattern of mate choice of L. fabalis in the populations studied may be considered as adaptive since most of the copulations were potentially productive. It proved to be well-isolated from L. obtusata, which is supported by high values of $\mathrm{I}_{\mathrm{PC}}$ and both female and male FI values. An effective PMI between $L$. fabalis and L. obtusata observed in our study agrees well with the results of genetic analyses showing a clear differentiation between these species ${ }^{80-82}$, with the exception of one population in Portugal ${ }^{83}$. Typical proteomes and metabolomes of $L$. fabalis and L. obtusata also show robust differences (in contrast to L. saxatilis vs L. arcana ${ }^{28,84}$ ). This phenomenon might also be related to effective reproductive isolation.

The observation of L. fabalis males with L. obtusata females (but not vice versa) in all three years of the analysis corresponds to the propensity of $L$. fabalis males to follow large females ${ }^{41,46}$. This is in line with the general tendency in gastropods and other invertebrates: males tend to be smaller than the females they mate ${ }^{85}$. Accordingly, in the populations analysed, L. obtusata females in copulating pairs were larger than the active L. fabalis males, which in general mated with larger passive partners. L. obtusata males also mated with slightly larger partners while L. fabalis females were mainly a bit smaller (Fig. 4). This attests that the shell size contributes to 
PMI between these two species, even though to a lesser extent than in the case of L. compressa vs L. arcana and L. saxatilis. The importance of size in the mate choice was also suggested to be a background for the reduced gene flow between L. fabalis ecotypes in Swedish populations ${ }^{46,86}$. These observations support the hypothesis that a shift in mean size, due to growth rate or maturation time, may facilitate the divergence of sister species in snails as it contributes to assortative mating within diverging morphs ${ }^{31,43,46}$.

Although shell size obviously contributes to mate choice in Littorina species, it cannot play a leading role in PMI due to significant overlap in size between the species, especially considering that copulations with young individuals are common. Other mechanisms such as differences in shell shape $e^{28,33,87}$ are probably involved as well. Nevertheless, it seems reasonable to conclude that the major factor preventing interspecies mating is differentiation of ecological niches: in populations of the studied region L. obtusata prefers to keep during low tide within A. nodosum canopy, while L. fabalis is mainly associated with open parts of F. serratus ${ }^{28}$. Together with a low dispersal ability, this differentiation provides a strong precondition for "by species"-assortative mating. The acquisition of different ecological preferences was probably a crucial event in the divergence between these species.

At the same time, premating barriers between $L$. fabalis and L. obtusata are not absolute, and some postmating mechanisms such as sperm competition or cryptic female choice should exist. Noteworthy, a protein factor presumably involved in PMPZ barriers (LOSP) was recently described in L. obtusata parasperm cells ${ }^{88,89}$. These cells together with attached spermatozoa bunches are transferred to the female during insemination and stored within the receptacle ${ }^{33,90}$. Paraspermal secretory proteins affect sperm survival, motility and fertilization success. Significant differences in LOSP structure were identified between L. fabalis and L. obtusata ${ }^{91}$, indicating its potential role in the maintenance of the reproductive barriers between these species.

Premating isolation within the "saxatilis" group. Within the "saxatilis" group of cryptic species, L. compressa snails were highly species-specific in copulations, in contrast to L. saxatilis and L. arcana. Differences in the microbiotopic distribution between L. compressa on the one hand and L. arcana and L. saxatilis on the other hand ${ }^{28,36}$ are the major factor separating L. compressa and uniting L. saxatilis and L. arcana in their copulative patterns.

Nonetheless, L. compressa populations spatially overlap with those of L. saxatilis and L. arcana along the intertidal zone. The shell size differences, again, fortify PMI. Indeed, copulating L. compressa individuals were significantly smaller than those of L. saxatilis and L. arcana (Fig. 4). The snails following the trail of a prospective mate ${ }^{92}$ can perceive chemical and mechanical cues, including the size of the snail that left the trail ${ }^{45,93}$. Pronounced differences in the size and the shape of the shell between the wave and the crab ecotypes of L. saxatilis are supposed to drive strong assortative mating ${ }^{31,50,94-96}$. In contrast, the ecotypes of $L$. fabalis are not so strongly differentiated by size and have a rather weak mating barrier ${ }^{46}$. Similarly, size differences might contribute to a mating barrier between L. compressa and L. saxatilis/L. arcana species pair.

The "arcana/saxatilis" paradox. Littorina arcana and L. saxatilis are a notable case, contrasting with the initial expectation of strong PMI between sympatric sister-species. These species are ecologically very similar (at least in high-shore ${ }^{28}$ ), and there are no records of L. arcana populations that are not sympatric with L. saxatilis ${ }^{33}$. These species resemble each other in shell shape, physiologically and genetically, and their populations overlap significantly as well ${ }^{28,34,36,59,61,84,97}$. In the populations studied, copulating individuals of these species were of a similar size and the males of these two species copulated with similar sets of passive partners, suggesting that PMI is weak. Frequent interspecific L. saxatilis/L. arcana copulations are probably associated with the lack of prominent ecological and shell size differences. Importantly, mating interactions between these species were asymmetric. Females of $L$. arcana were largely ignored by the males of both L. arcana and L. saxatilis (as well as by $L$. saxatilis 1.5 row males). Out of the 25 pairs involving $L$. arcana males, only three pairs involved $L$. arcana females (Table 2). A low proportion of L. arcana females engaged in mating is striking, because the sex ratio in the analysed L. arcana populations was in favour of the females (Supplement S3,S4).

Littorina arcana females were the rarest passive partners in the all pairs, including L. arcana and/or L. saxatilis (Table 2) and as a consequence had a negative FI value (Supplement S7). A possible explanation of this pattern is that L. arcana females, though morphologically indistinguishable, were represented by a mixture of "pure" and "hybrid" (L. arcana/L. saxatilis) individuals in the populations under study. These "pure" and "hybrid" individuals significantly varied in their attractiveness for the males of both L. arcana and L. saxatilis. This interpretation is compatible with the results of Warwick et al. ${ }^{63}$, who showed that hybrid "arcana/saxatilis" females (resulting from breeding of $L$. saxatilis males with $L$. arcana females but not vice versa) had $L$. arcana morphology.

This hypothesis is supported by direct and indirect evidence on the possibility of asymmetric hybridization between these species. The possibility of one-directional hybridization between them (but not with L. compressa in any combination) was first demonstrated in laboratory experiments that yielded viable and fecund offspring with normal segregation of parental alleles in the next generations $s^{63,98}$. The distribution pattern of the L. arcana specific locus A2.8 (revealed by comparative RAPD analysis) also implied the possibility of limited gene flow between $L$. arcana and L. saxatilis and the existence of viable hybrids in the wild ${ }^{61}$. An exhaustive analysis of microspatial distribution of these two species and their presumably hybrids across a vertical shore gradient showed a clear correlation between the frequencies of L. arcana and presumably hybrids in populations. Interestingly, the interspecific gene flow was shown to fit an asymmetric model, where both "pure" L. saxatilis and rare hybrid "arcana/saxatilis" females were involved in hybridization, while "pure" L. arcana females were not ${ }^{36}$. Thus, the L. arcana females engaged in the copulations in this study might correspond to "hybrid" females while the rest of the females, ignored by males (e.g., due to reproductive seasonality), could be "pure" L. arcana females. This hypothesis might be verified in studies involving genome-wide analyses to qualify true differences between morphologically indistinguishable L. arcana and hybrid females. Our interpretations are in concordance with the predictions by Warwick et al. ${ }^{63}$ that the percentage of hybrid "arcana/saxatilis" females in the wild populations 
should be low, not more $2 \%$. An asymmetric genome-wide introgression from L. saxatilis to L. arcana was also inferred in a recent study ${ }^{64}$, though the authors did not reveal any direct interspecies hybrids among 3092 genotyped individuals, which was possibly a specific feature of the populations studied.

Noteworthy, the gap in PMI in the nature observed in our study (L. arcana males actively mate with L. saxatilis females) was an exact opposite of the gap in PMPZ isolation detected in the laboratory (L. saxatilis successfully cross with L. arcana females, but not reciprocally). This resembles an asymmetric PMI between allopatric populations of Drosophila montan ${ }^{15}$, where the pre- and postmating barriers compensated for each other's weakness: PMPZ were effective only in combinations with weak PMI and vice versa. In the case of L. arcanal L. saxatilis species pair, several reproductive barriers function asymmetrically as well. Some of them are weak, eventually allowing some leakage of genes from L. arcana to L. saxatilis (as revealed with A2.8 marker ${ }^{61}$ ). It was demonstrated that species isolated by a large number of weak reproductive barriers have a more complicated genetic architecture than strongly isolated ones ${ }^{99}$. This forms a favourable background for a detailed comparative analysis of $L$. saxatilis populations either accompanied or not by L. arcana, including aspects of potential PMPZ isolation mechanisms. A paraspermal protein LOSP, potentially involved in the maintenance of postcopulatory reproductive barriers, was recently characterized in the Littorina (Neritrema) species ${ }^{88,89}$. Noteworthy, this protein demonstrates a high degree of polymorphism in the L. saxatilis/L. arcana pair, where PMI is weak, unlike L. obtusata, which is well isolated from the other species at the premating level ${ }^{91}$.

\section{Summary, conclusions and perspectives}

We analysed the premating reproductive isolation in a post-speciation model involving a group of recently diverged sympatric species. We showed that five evolutionarily young species do vary in the strength of PMI. With one notable exception, heterospecific heterosexual copulations were not typical though they do occur in the wild at a low rate. Our results are particularly interesting in the context of an upcoming study, where we demonstrate clear differences in microhabitat preferences for all species pairs except L. arcana/L. saxatilis ${ }^{28}$. We previously compared molecular phenotypes in the context of phylogenetic closeness of those species, with an exceptionally high degree of similarity between L. saxatilis/L. arcana ${ }^{84}$. Species of this pair have similar ecological preferences in the upper intertidal level, and their males copulate with similar sets of passive partners. Finally, there is a clear correspondence between the degree of differentiation of ecological niches, the degree of molecular phenotype dissimilarity, and the efficacy of PMI. Altogether, this suggests a major, and most probably evolutionarily primary role of habitat choice in the PMI maintenance between Littorina species. This, in turn, lends support to the hypothesis of the origin of these species by sympatric ecological speciation with a limited gene flow via niche differentiation within the intertidal zone. Life in a certain type of microhabitat combined with a low dispersal (due to low motility and absence of planktonic larvae) possibly served as a prerequisite for assortative mating, which occurs via habitat choice. This promoted accumulation of adaptive traits such as shell shape, size, proteomic and metabolomic characteristics, while mate choice joined as a secondary acting force based on matching rule, when traits listed above were important (not only conspecific females, but also conspecific males were mated more often than heterospecific ones). Finally, these factors together strengthened the divergence between incipient species, and acted as a powerful force increasing the probability of a successful speciation event ${ }^{9,10,12,100}$. This scenario appears quite plausible for the European North Atlantic Neritrema species with clearly diverged ecological preferences. Interestingly, the species of passive partner in the Littorina populations studied was recognized with a greater accuracy in females than in males. This indicates that mate choice based on preference/trait rule ${ }^{12}$ may also contribute to PMI between Littorina (Neritrema) species.

The pair L. arcana and L. saxatilis demonstrated a peculiar mating pattern, with both species showing preference for $L$. saxatilis females. There were no differences in shell size and shape between these two species ${ }^{28}$. They are also similar ecologically and at proteomic and metabolomic levels ${ }^{28,84,97}$. Thus, habitat choice and adaptation to microenvironment hardly explain the background of divergence between these species. Importantly, the males of $L$. arcana demonstrated a significantly higher rate of both homosexual and heterospecific copulations among all species studied. This implies that (1) the males of this species are more indiscriminate in their choice of passive partners, causing inefficacy in PMI and (2) other barriers, e.g., some mechanisms of PMPZ such as differential sperm viability, motility, transfer, storage or usage, physical and chemical cues interfering sperm guidance, gamete fusion, and eventual formation of a zygote ${ }^{101}$ may play a crucial role in the divergence of this species pair. Thus, the analysis of PMPZ mechanisms in the Littorina (Neritrema) species is a promising direction of future studies.

Received: 16 November 2020; Accepted: 15 February 2021

Published online: 11 March 2021

\section{References}

1. Mayr, E. Ecological factors in speciation. Evolution https://doi.org/10.1111/j.1558-5646.1947.tb02723.x (1947)

2. Coyne, J. A. \& Orr, H. A. Speciation Vol. 38 (Sinauer Associates, Sunderland MA, 2004).

3. Rosenblum, E. B. et al. Goldilocks meets Santa Rosalia: An ephemeral speciation model explains patterns of diversification across time scales. Evol. Biol. 39, 255-261. https://doi.org/10.1007/s11692-012-9171-x (2012).

4. Dobzhansky, T. Genetics and the Origin of Species (Columbia University Press, Columbia, 1937).

5. Edmands, S. Does parental divergence predict reproductive compatibility?. Trends Ecol. Evol. 17, 520-527. https://doi. org/10.1016/S0169-5347(02)02585-5 (2002).

6. Turissini, D. A., McGirr, J. A., Patel, S. S., David, J. R. \& Matute, D. R. The rate of evolution of postmating-prezygotic reproductive isolation in Drosophila. Mol. Biol. Evol. 35, 312-334. https://doi.org/10.1093/molbev/msx271 (2018).

7. Nosil, P., Vines, T. H. \& Funk, D. J. Reproductive isolation caused by natural selection against immigrants from divergent habitats. Evolution 59, 705-719. https://doi.org/10.1111/j.0014-3820.2005.tb01747.x (2005). 
8. Crespi, B. J. Causes of assortative mating in arthropods. Anim. Behav. 38, 980-1000. https://doi.org/10.1016/S0003-3472(89)80138 -1 (1989).

9. Smadja, C. M. \& Butlin, R. K. A framework for comparing processes of speciation in the presence of gene flow. Mol. Ecol. 20, 5123-5140. https://doi.org/10.1111/j.1365-294X.2011.05350.x (2011).

10. Servedio, M. R. Geography, assortative mating, and the effects of sexual selection on speciation with gene flow. Evol. Appl. 9, 91-102. https://doi.org/10.1111/eva.12296 (2016).

11. Merot, C., Salazar, C., Merrill, R. M., Jiggins, C. D. \& Joron, M. What shapes the continuum of reproductive isolation? Lessons from Heliconius butterflies. Proc. R. Soc. B Biol. Sci. 284, 20170335. https://doi.org/10.1098/rspb.2017.0335 (2017).

12. Kopp, M. et al. Mechanisms of assortative mating in speciation with gene flow: connecting theory and empirical research. Am. Nat. 191, 1-20. https://doi.org/10.1086/694889 (2018).

13. Janicke, T., Marie-Orleach, L., Aubier, T. G., Perrier, C. \& Morrow, E. H. Assortative mating in animals and its role for speciation. Am. Nat. 194, 865-875. https://doi.org/10.1086/705825 (2019).

14. Richards, E. J., Servedio, M. R. \& Martin, C. H. Searching for sympatric speciation in the genomic era. BioEssays 41, 1900047. https://doi.org/10.1002/bies.201900047 (2019).

15. Jennings, J. H., Snook, R. R. \& Hoikkala, A. Reproductive isolation among allopatric Drosophila montana populations. Evolution 68, 3095-3108. https://doi.org/10.1111/evo.12535 (2014).

16. Alipaz, J. A., Wu, C. \& Karr, T. L. Gametic incompatibilities between races of Drosophila melanogaster. Proc. R. Soc. Lond. B https://doi.org/10.1098/rspb.2000.1420 (2001).

17. McQuaid, C. D. \& Dower, K. M. Enhancement of habitat heterogeneity and species richness on rocky shores inundated by sand. Oecologia 84, 142-144. https://doi.org/10.1007/BF00665608 (1990).

18. Archambault, P. \& Bourget, E. Scales of coastal heterogeneity and benthic intertidal species richness, diversity and abundance. Mar. Ecol. Prog. Ser. 136, 111-121. https://doi.org/10.3354/meps136111 (1996).

19. de Forges, B. R., Koslow, J. A. \& Poore, G. C. B. Diversity and endemism of the benthic seamount fauna in the southwest Pacific. Nature 405, 944-947. https://doi.org/10.1038/35016066 (2000).

20. Hooper, D. U. et al. Effects of biodiversity on ecosystem functioning: a consensus of current knowledge. Ecol. Monogr. 75, 3-35. https://doi.org/10.1890/04-0922 (2005).

21. Williams, S. T. \& Reid, D. G. Speciation and diversity on tropical rocky shores: a global phylogeny of snails of the genus Echinolittorina. Evolution 58, 2227-2251. https://doi.org/10.1111/j.0014-3820.2004.tb01600.x (2004).

22. Frey, M. A. The relative importance of geography and ecology in species diversification: evidence from a tropical marine intertidal snail (Nerita). J. Biogeogr. 37, 1515-1528. https://doi.org/10.1111/j.1365-2699.2010.02283.x (2010).

23. Pereyra, R. T., Bergström, L., Kautsky, L. \& Johannesson, K. Rapid speciation in a newly opened postglacial marine environment, the Baltic Sea. BMC Evol. Biol. 9, 70. https://doi.org/10.1186/1471-2148-9-70 (2009).

24. Cánovas, F. G., Mota, C. F., Serrão, E. A. \& Pearson, G. A. Driving south: A multi-gene phylogeny of the brown algal family Fucaceae reveals relationships and recent drivers of a marine radiation. BMC Evol. Biol. 11, 371. https://doi.org/10.1186/14712148-11-371 (2011).

25. Coyer, J. A. et al. Evolution and diversification within the intertidal brown macroalgae Fucus spiralis/F. vesiculosus species complex in the North Atlantic. Mol. Phylogenet. Evol. 58, 283-296. https://doi.org/10.1016/j.ympev.2010.11.015 (2011).

26. Robinson, J. D. \& Dillon, R. T. Genetic divergence among sympatric populations of three species of oyster drills (Urosalpinx) in Cedar Key Florida. Bull. Mar. Sci. 82, 19-31 (2008).

27. Wares, J. P. Intraspecific variation and geographic isolation in Idotea balthica (Isopoda: Valvifera). J. Crustac. Biol. 21, 1007-1013. https://doi.org/10.1163/20021975-99990193 (2001).

28. Maltseva, A. L. et al. Microhabitat distribution, shell shape, and metabolomes in sympatric populations of closely related species of the genus Littorina (Neritrema) in two sites in the Norwegian and Barents Sea. PeerJ https://doi.org/10.1594/PANGA EA.923735 (2021).

29. Pickles, A. \& Grahame, J. Mate choice in divergent morphs of the gastropod mollusc Littorina saxatilis (Olivi): speciation in action?. Anim. Behav. 58, 181-184. https://doi.org/10.1006/anbe.1999.1115 (1999).

30. Erlandsson, J. Do reproductive strategy and breeding season influence the presence of mate recognition in the intertidal snail Littorina?. Invertebr. Reprod. Dev. 41, 53-60. https://doi.org/10.1080/07924259.2002.9652735 (2002).

31. Johannesson, K. et al. Male discrimination of female mucous trails permits assortative mating in a marine snail species. Evolution 62, 3178-3184. https://doi.org/10.2307/25483552 (2008).

32. Ng, T. P. \& Johannesson, K. No precopulatory inbreeding avoidance in the intertidal snail Littorina saxatilis. J. Molluscan Stud. 82, 213-215. https://doi.org/10.1093/mollus/eyv035 (2016).

33. Reid, D. G. Systematics and evolution of Littorina. vol. 164 (The Ray Society, 1996).

34. Granovitch, A. I., Mikhailova, N. A., Znamenskaya, O. \& Petrova, Y. A. Species complex of mollusks of the genus Littorina (Gastropoda, Prosobranchia) from the eastern Murman coast. Zool. Z. 83, 1305-1316 (2004) (In Russian).

35. Reid, D. G., Dyal, P. \& Williams, S. T. A global molecular phylogeny of 147 periwinkle species (Gastropoda, Littorininae). Zool. Scr. 41, 125-136. https://doi.org/10.1111/j.1463-6409.2011.00505.x (2012).

36. Granovitch, A. I., Maximovich, A. N., Avanesyan, A. V., Starunova, Z. I. \& Mikhailova, N. A. Micro-spatial distribution of two sibling periwinkle species across the intertidal indicates hybrdization. Genetica 141, 293-301. https://doi.org/10.1007/s1070 9-013-9728-3 (2013).

37. Raffaelli, D. G. Observations of the copulatory behavior of Littorina rudis Maton and Littorina nigrolineata Gray (Gastropoda: Prosobranchia). Veliger 20, 75-77. https://doi.org/10.1007/BF00028082 (1977).

38. Saur, M. Mate discrimination in Littorina littorea (L.) and L. saxatilis (Olivi) (Mollusca:Prosobranchia). Hydrobiologia 193, 261-270. https://doi.org/10.1007/BF00028082 (1990).

39. Erlandsson, J. \& Johannesson, K. Sexual selection on female size in a marine snail, Littorina littorea (L.). J. Exp. Mar. Biol. Ecol. 181, 145-157. https://doi.org/10.1016/0022-0981(94)90125-2 (1994).

40. Johannesson, K., Rolán-Alvarez, E. \& Ekendahl, A. Incipient reproductive isolation between two sympatric morphs of the intertidal snail Littorina saxatilis. Evolution 49, 1180-1190. https://doi.org/10.1111/j.1558-5646.1995.tb04445.x (1995).

41. Rolán-Alvarez, E., Zapata, C. \& Alvarez, G. Multilocus heterozygosity and sexual selection in a natural population of the marine snail Littorina mariae (Gastropoda: Prosobranchia). Heredity 75, 17-25. https://doi.org/10.1038/hdy.1995.99 (1995).

42. Erlandsson, J. \& Rolán-Alvarez, E. Sexual selection and assortative mating by size and their roles in the maintenance of a polymorphism in Swedish Littorina saxatilis populations. Hydrobiologia 378, 59-69. https://doi.org/10.1023/A:1003277202763 (1998).

43. Rolán-Alvarez, E., Erlandsson, J., Johannesson, K. \& Cruz, R. Mechanisms of incomplete prezygotic reproductive isolation in an intertidal snail: testing behavioural models in wild populations. J. Evol. Biol. 12, 879-890. https://doi.org/10.104 6/j.1420-9101.1999.00086.x (1999).

44. Johannesson, K., Saltin, S. H., Duranovic, I., Havenhand, J. N. \& Jonsson, P. R. Indiscriminate males: Mating behaviour of a marine snail compromised by a sexual conflict?. PLoS ONE 5, e12005. https://doi.org/10.1371/journal.pone.0012005 (2010).

45. Ng, T. P. T., Davies, M. S., Stafford, R. \& Williams, G. A. Mucus trail following as a mate-searching strategy in mangrove littorinid snails. Anim. Behav. 82, 459-465. https://doi.org/10.1016/j.anbehav.2011.05.017 (2011).

46. Saltin, S. H. Mate Choice and Its Evolutionary Consequences in Intertidal Snails (Littorina spp.). (Thesis for the degree of Doctor of Philosophy). Gothenburg, Sweden: University of Gothenburg. (2013). 
47. Estévez, D. et al. A novel method to estimate the spatial scale of mate choice in the wild. Behav. Ecol. Sociobiol. 72, 195. https:// doi.org/10.1007/s00265-018-2622-3 (2018).

48. Carvajal-Rodríguez, A. Multi-model inference of non-random mating from an information theoretic approach. Theor. Popul. Biol. 131, 38-53. https://doi.org/10.1016/j.tpb.2019.11.002 (2020).

49. Perini, S., Rafajlović, M., Westram, A. M., Johannesson, K. \& Butlin, R. K. Assortative mating, sexual selection, and their consequences for gene flow in Littorina. Evolution 74, 1482-1497. https://doi.org/10.1111/evo.14027 (2020).

50. Hollander, J., Lindegarth, M. \& Johannesson, K. Local adaptation but not geographical separation promotes assortative mating in a snail. Anim. Behav. 70, 1209-1219. https://doi.org/10.1016/j.anbehav.2005.03.014 (2005).

51. Merrell, D. J. Measurement of sexual isolation and selective mating. Evolution https://doi.org/10.2307/2405599 (1950).

52. Rolán-Alvarez, E. \& Caballero, A. Estimating sexual selection and sexual isolation effects from mating frequencies. Evolution 54, 30-36. https://doi.org/10.1111/j.0014-3820.2000.tb00004.x (2000).

53. Ter Braak, C. J. F. Partial canonical correspondence analysis. In Classification and Related Methods of data Analysis: Proceedings of the First Conference of the International Federation of Classification Societies (IFCS), Technical University of Aachen, FRG, 29 June-1 July 1987 551-558 (Elsevier, 1988).

54. Legendre, P. \& Legendre, L. Numerical Ecology Vol. 24 (Elsevier, Amsterdam, 2012).

55. Hannaford Ellis, C. J. Patterns of reproduction in four Littorina species. J. Molluscan Stud. 49, 98-106. https://doi.org/10.1093/ oxfordjournals.mollus.a065711 (1983).

56. Sokolova, I. M. Influence of trematodes on the demography of Littorina saxatilis (Gastropoda: Prosobranchia: Littorinidae) in the White Sea. Dis. Aquat. Organ. 21, 91-101. https://doi.org/10.3354/dao021091 (1995).

57. Hull, S. L., Grahame, J. \& Mill, P. J. Reproduction in four populations of brooding periwinkle (Littorina) at Ravenscar, North Yorkshire: Adaptation to the local environment?. J. Mar. Biol. Assoc. 79, 891-898. https://doi.org/10.1017/S0025315499001058 (1999).

58. Ganzha, E. V., Granovitch, A. I., Petrova, Y. A. \& Mikhailova, N. A. Hystological analysis of penial glands of Littorina mollusks. Vestn. -Peterbg. Univ. 3, 40-46 (2006) (In Russian).

59. Granovitch, A. I., Loskutova, Z. I., Gracheva, Y. A. \& Mikhailova, N. A. Morphometric comparison of the copulatory organ in mollusks of 'saxatilis' species complex (Caenogastropoda: Littorinidae): problems of identification of species and species status. Zool. Z. 87, 1425-1436 (2008).

60. Mikhailova, N. A., Gracheva, Y. A. \& Granovitch, A. I. Analysis of the interspecific mating frequency in the copulating pairs of the marine gastropods genus Littorina in "saxatilis" complex. Vestn. St Petersburg State Univ. 3, 5-9 (2008) (In Russian).

61. Mikhailova, N. A., Gracheva, Y. A., Backeljau, T. \& Granovitch, A. I. A potential species-specific molecular marker suggests interspecific hybridization between sibling species Littorina arcana and L. saxatilis (Mollusca, Caenogastropoda) in natural populations. Genetica 137, 333. https://doi.org/10.1007/s10709-009-9397-4 (2009).

62. Reid, D. G. Barnacle-dwelling ecotypes of three British Littorina species and the status of Littorina neglecta Bean. J. Molluscan Stud. 59, 51-62. https://doi.org/10.1093/mollus/59.1.51 (1993).

63. Warwick, T., Knight, A. \& Ward, R. Hybridisation in the Littorina saxatilis species complex (Prosobranchia: Mollusca). Hydrobiologia 193, 109-116. https://doi.org/10.1007/BF00028070 (1990).

64. Stankowski, S. et al. The evolution of strong reproductive isolation between sympatric intertidal snails. Philos. Trans. R. Soc. B 375, 20190545. https://doi.org/10.1098/rstb.2019.0545 (2020).

65. Rolán-Alvarez, E. et al. The scale-of-choice effect and how estimates of assortative mating in the wild can be biased due to heterogeneous samples. Evolution 69, 1845-1857. https://doi.org/10.1111/evo.12691 (2015).

66. Ng, T. P. T., Williams, G. A., Davies, M. S., Stafford, R. \& Rolán-Alvarez, E. Sampling scale can cause bias in positive assortative mating estimates: Evidence from two intertidal snails. Biol. J. Linn. Soc. 119, 414-419. https://doi.org/10.1111/bij.12839 (2016).

67. Mirkin, B. Mathematical Classification and Clustering (Springer Science \& Business Media, Berlin, 1996).

68. Rand, W. M. Objective criteria for the evaluation of clustering methods. J. Am. Stat. Assoc. 66, 846-850. https://doi. org/10.2307/2284239 (1971).

69. Galili, T. dendextend: an R package for visualizing, adjusting and comparing trees of hierarchical clustering. Bioinformatics $\mathbf{3 1}$, 3718-3720. https://doi.org/10.1093/bioinformatics/btv428 (2015).

70. R Core Team. R: A language and environment for statistical computing. Version 3.6.0. (R Foundation for Statistical Computing, 2019).

71. RStudio Team. RStudio: Integrated Development Environment for R. (2019).

72. Borcard, D., Gillet, F. \& Legendre, P. Numerical Ecology with R (Springer-Verlag, New York, 2011).

73. Oksanen, J. et al. vegan: Community Ecology Package. R Package Version 2.5-5. (2019).

74. Bateman, A. J. Analysis of data on sexual isolation. Evolution https://doi.org/10.1111/j.1558-5646.1949.tb00017.x (1949).

75. Pérez-Figueroa, A., Caballero, A. \& Rolán-Alvarez, E. Comparing the estimation properties of different statistics for measuring sexual isolation from mating frequencies. Biol. J. Linn. Soc. 85, 307-318. https://doi.org/10.1111/j.1095-8312.2005.00491.x (2005).

76. Wheeler, B. \& Torchiano, M. ImPerm: Permutation Tests for Linear Models. R Package Version 2.1-0. (2016).

77. Maxwell, S. E., Delaney, H. D. \& Kelley, K. Designing Experiments and Analyzing Data: A model Comparison Perspective (Routledge, London, 2017).

78. Wickham, H. ggplot2: Elegant Graphics for Data Analysis (Springer-Verlag, New York, 2016).

79. Struhsaker, J. W. Breeding, spawning, spawning periodicity and early development in the Hawaiian Littorina: L. pintado (Wood), L. picta Philippi and L. scabra (Linné). J. Molluscan Stud. 37, 137-166. https://doi.org/10.1093/oxfordjournals.mollus.a064985 (1966).

80. Kemppainen, P., Panova, M., Hollander, J. \& Johannesson, K. Complete lack of mitochondrial divergence between two species of NE Atlantic marine intertidal gastropods. J. Evol. Biol. 22, 2000-2011. https://doi.org/10.1111/j.1420-9101.2009.01810.x (2009).

81. Carvalho, J. et al. De novo isolation of 17 microsatellite loci for flat periwinkles (Littorina fabalis and L. obtusata) and their application for species discrimination and hybridization studies. J. Molluscan Stud. 81, 421-425. https://doi.org/10.1093/mollu s/eyv014 (2015).

82. Costa, D. et al. Hybridization patterns between two marine snails, Littorina fabalis and L. obtusata. Ecol. Evol. 10, 1158-1179. https://doi.org/10.1002/ece3.5943 (2020).

83. Carvalho, J., Sotelo, G., Galindo, J. \& Faria, R. Genetic characterization of flat periwinkles (Littorinidae) from the Iberian Peninsula reveals interspecific hybridization and different degrees of differentiation. Biol. J. Linn. Soc. 118, 503-519. https://doi. org/10.1111/bij.12762 (2016).

84. Maltseva, A. L. et al. Proteomic similarity of the Littorinid snails in the evolutionary context. PeerJ 8, e8546. https://doi. org/10.7717/peerj.8546 (2020).

85. Ng, T. P. et al. The causal relationship between sexual selection and sexual size dimorphism in marine gastropods. Anim. Behav. 148, 53-62. https://doi.org/10.1016/j.anbehav.2018.12.005 (2019).

86. Tatarenkov, A. \& Johannesson, K. Evidence of a reproductive barrier between two forms of the marine periwinkle Littorina fabalis (Gastropoda). Biol. J. Linn. Soc. 63, 349-365. https://doi.org/10.1111/j.1095-8312.1998.tb01522.x (1998).

87. Carvalho, J. G. M. Study on the Diversification of Flat Periwinkles (Littorina fabalis and L. obtusata): Insights from Genetics and Geometric Morphometrics. Doctoral Dissertation (2014). 
88. Lobov, A. A., Maltseva, A. L., Mikhailova, N. A. \& Granovitch, A. I. LOSP: A newly identified sperm protein from Littorina obtusata. J. Molluscan Stud. 81, 512-515. https://doi.org/10.1093/mollus/eyv010 (2015).

89. Lobov, A. A. et al. LOSP: A putative marker of parasperm lineage in male reproductive system of the prosobranch mollusk Littorina obtusata. J. Exp. Zool. B 330, 193-201. https://doi.org/10.1002/jez.b.22803 (2018).

90. Buckland-Nicks, J. A., Healy, J. M., Jamieson, B. G. M. \& O'Leary, S. Paraspermatogenesis in Littoraria (Palustorina) articulata, with reference to other Littorinidae (Littorinoidea, Caenogastropoda). Invertebr. Biol. 119, 254-264. https://doi. org/10.1111/j.1744-7410.2000.tb00012.x (2000).

91. Lobov, A. Gamete interaction proteins as factors of reproductive isolation of cryptic species of the genus Littorina Férussac, 1822. Thesis for the degree of Candidate of Biological Sciences. St.-Petersburg State University. https://doi.org/10.13140/RG.2.2.16769.68968. (2020).

92. Ng, T. P. et al. Snails and their trails: the multiple functions of trail-following in gastropods. Biol. Rev. 88, 683-700. https://doi. org/10.1111/brv.12023 (2013).

93. Erlandsson, J. \& Kostylev, V. Trail following, speed and fractal dimension of movement in a marine prosobranch, Littorina littorea, during a mating and a non-mating season. Mar. Biol. 122, 87-94. https://doi.org/10.1007/BF00349281 (1995).

94. Rolán-Alvarez, E. et al. Nonallopatric and parallel origin of local reproductive barriers between two snail ecotypes. Mol. Ecol. 13, 3415-3424. https://doi.org/10.1111/j.1365-294X.2004.02330.x (2004).

95. Grahame, J. W., Wilding, C. S. \& Butlin, R. K. Adaptation to a steep environmental gradient and an associated barrier to gene exchange in Littorina saxatilis. Evolution 60, 268-278. https://doi.org/10.1111/j.0014-3820.2006.tb01105.x (2006).

96. Panova, M., Hollander, J. \& Johannesson, K. Site-specific genetic divergence in parallel hybrid zones suggests nonallopatric evolution of reproductive barriers. Mol. Ecol. 15, 4021-4031. https://doi.org/10.1111/j.1365-294X.2006.03067.x (2006).

97. Maltseva, A. L. et al. Measuring physiological similarity of closely related littorinid species: A proteomic insight. Mar. Ecol. Prog. Ser. 552, 177-193. https://doi.org/10.3354/meps11770 (2016).

98. Ward, R. D., Warwick, T. \& Knight, A. J. Genetic analysis of ten polymorphic enzyme loci in Littorina saxatilis (Prosobranchia: Mollusca). Heredity 57, 233-241. https://doi.org/10.1038/hdy.1986.113 (1986).

99. Dopman, E. B., Robbins, P. S. \& Seaman, A. Components of reproductive isolation between North American pheromone strains of the European corn borer. Evol. Int. J. Org. Evol. 64, 881-902. https://doi.org/10.1111/j.1558-5646.2009.00883.x (2010).

100. Weissing, F. J., Edelaar, P. \& Van Doorn, G. S. Adaptive speciation theory: A conceptual review. Behav. Ecol. Sociobiol. 65, 461-480. https://doi.org/10.1007/s00265-010-1125-7 (2011).

101. Lobov, A., Maltseva, A., Mikhailova, N. \& Granovitch, A. The molecular mechanisms of gametic incompatibility in invertebrates. Acta Nat. 11, 4-15 (2019).

\section{Acknowledgements}

This research was funded by the Russian Science Foundation, grant number 19-14-00321 PI Andrei I. Granovitch. The opportunities for maintenance of experimental animals were provided by the Resource Centre Environmental Safety Observatory of St Petersburg State University. We are grateful to Natalia V. Lentsman for the thorough review and proofreading of the manuscript, as well as to Dr. Emilio Rolán-Alvarez for the valuable comments.

\section{Author contributions}

A.L.M. conceived and designed the study, collected raw data, analysed the data, prepared figures and tables, wrote the primary draft of the paper, reviewed drafts of the paper, funding acquisition. M.A.V. conceived and designed the strategy of the data analysis, performed statistical analysis of all the data, prepared figures and tables, reviewed drafts of the paper, proof-read and approved the final draft. A.A.L. collected raw data, reviewed drafts of the paper, and approved the final draft. P.T. collected raw data, reviewed drafts of the paper, and approved the final draft. E.A.R., collected raw data, took and prepared photographs, reviewed drafts of the paper, and approved the final draft. I.Y.B. collected raw data, reviewed drafts of the paper, and approved the final draft. M.P. analysed the data, reviewed drafts of the paper, proof-read and approved the final draft. N.A.M. conceived and designed the experiments, collected raw data, reviewed drafts of the paper, and approved the final draft, funding acquisition. A.I.G. conceived and designed the study, collected row data, analysed the data, reviewed drafts of the paper, and approved the final draft, funding acquisition.

\section{Competing interests}

The authors declare no competing interests.

\section{Additional information}

Supplementary Information The online version contains supplementary material available at https://doi. org/10.1038/s41598-021-84407-2.

Correspondence and requests for materials should be addressed to A.L.M.

Reprints and permissions information is available at www.nature.com/reprints.

Publisher's note Springer Nature remains neutral with regard to jurisdictional claims in published maps and institutional affiliations.

\footnotetext{
Open Access This article is licensed under a Creative Commons Attribution 4.0 International License, which permits use, sharing, adaptation, distribution and reproduction in any medium or format, as long as you give appropriate credit to the original author(s) and the source, provide a link to the Creative Commons licence, and indicate if changes were made. The images or other third party material in this article are included in the article's Creative Commons licence, unless indicated otherwise in a credit line to the material. If material is not included in the article's Creative Commons licence and your intended use is not permitted by statutory regulation or exceeds the permitted use, you will need to obtain permission directly from the copyright holder. To view a copy of this licence, visit http://creativecommons.org/licenses/by/4.0/.
}

(C) The Author(s) 2021 